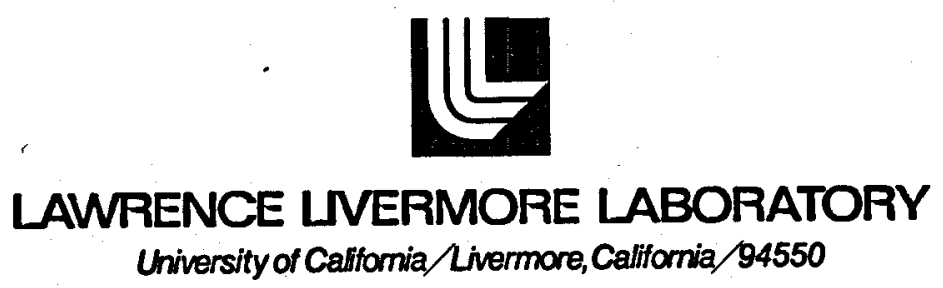

UCRL-52797

\title{
THE POTENTIAL AIR QUALITY IMPACT OF GEOTHERMAL POWER PRODUCTION IN THE IMPERIAL VALLEY
}

P. H. Gudiksen, D. L. Ermak, K. C. Lamson, M. C. Axelrod, and R. A. Nyholm

Manuscript date: October, 1979 


\section{DISCLAIMER}

This report was prepared as an account of work sponsored by an agency of the United States Government. Neither the United States Government nor any agency Thereof, nor any of their employees, makes any warranty, express or implied, or assumes any legal liability or responsibility for the accuracy, completeness, or usefulness of any information, apparatus, product, or process disclosed, or represents that its use would not infringe privately owned rights. Reference herein to any specific commercial product, process, or service by trade name, trademark, manufacturer, or otherwise does not necessarily constitute or imply its endorsement, recommendation, or favoring by the United States Government or any agency thereof. The views and opinions of authors expressed herein do not necessarily state or reflect those of the United States Government or any agency thereof. 


\section{DISCLAIMER}

Portions of this document may be illegible in electronic image products. Images are produced from the best available original document. 


\section{CONTENTS}

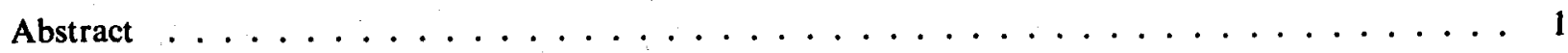

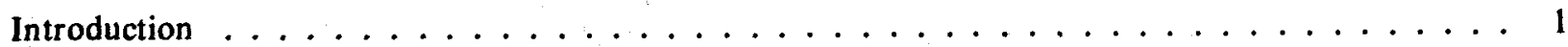

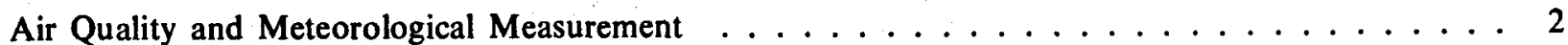

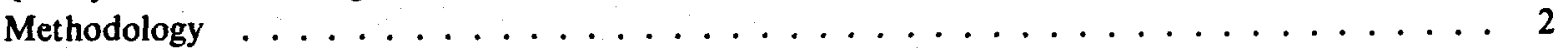

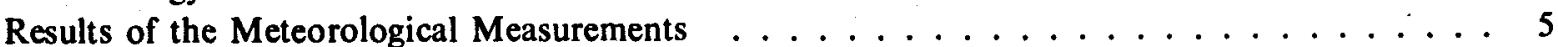

Results of the Air Quality Measurements . . . . . . . . . . . . . . 7

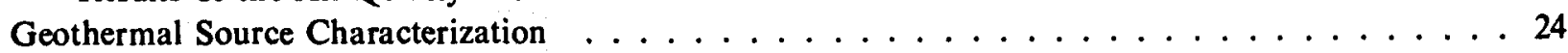

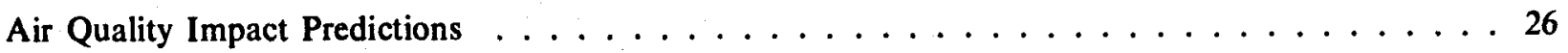

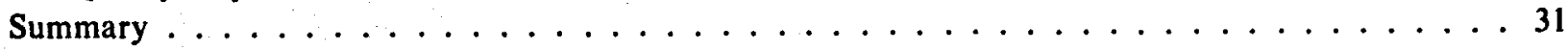

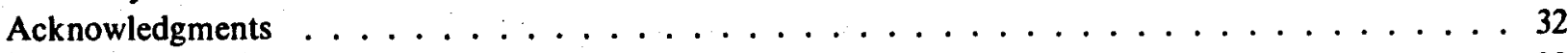

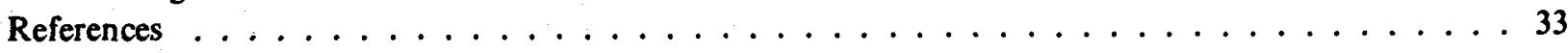

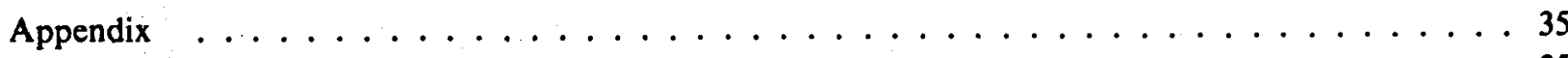

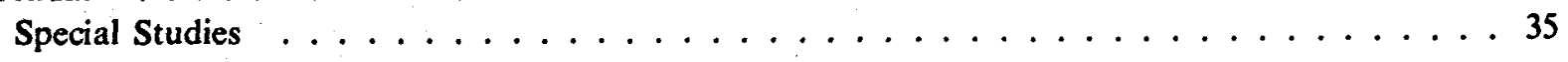




\title{
THE POTENTIAL AIR QUALITY IMPACT OF GEOTHERMAL POWER PRODUCTION IN THE IMPERIAL VALLEY
}

\begin{abstract}
This report is a regional assessment of the potential impact on air quality of developing the Imperial Valley's geothermal resources for power production. A network of six stations was installed to characterize the air quality and atmospheric transport properties of the valley before development. These measured the ambient air concentrations of $\mathrm{H}_{2} \mathrm{~S}, \mathrm{SO}_{2}, \mathrm{O}_{3}, \mathrm{NO}, \mathrm{NO}_{\mathrm{x}}, \mathrm{CO}_{2}, \mathrm{Hg}, \mathrm{Rn}$, and particulates. Wind velocity and the directional variability of the winds were also measured to determine atmospheric stability. The geothermal fluids were analyzed chemically to estimate potential emission rates of $\mathrm{H}_{2} \mathrm{~S}, \mathrm{NH}_{3}, \mathrm{CO}_{2}$, $\mathrm{CH}_{4}, \mathrm{Hg}$, and $\mathrm{Rn}$ from future power plants. Using these data and advanced air quality modeling led to the prediction of the potential valley-wide impact of a $3000 \mathrm{MW}$ development scenario.

The impact analysis reveals that $\mathrm{H}_{2} \mathrm{~S}$ is the principal gaseous pollutant of concern due to its noxious odor and the potential release rate. The ambient $\mathrm{H}_{2} \mathrm{~S}$ concentrations that would result from generating $3000 \mathrm{MW}$ without emission controls exceed the California air quality standard $(30 \mathrm{ppb})$ at least $1 \%$ of the time for an area in the northern part of the valley that is roughly $1500 \mathrm{~km}^{2}$ in size. This compares with current ambient air concentrations that exceed the standard much less than $0.1 \%$ of the time. The population center most impacted is Calipatria, where the standard could be exceeded almost $10 \%$ of the time. In addition, the odor of $\mathrm{H}_{2} \mathrm{~S}$ will be noticeable at least $1 \%$ of the time for most of the valley if the $3000 \mathrm{MW}$ are placed on-line without abatement systems.
\end{abstract}

\section{INTRODUCTION}

The Imperial Valley in Southern California has a considerable geothermal resource that might be used for commercial power production. The Imperial Valley Environmental Project assessed the potential effects of developing this resource; its aim was to ensure that any development proceeds in an environmentally acceptable manner. An integral part of this project is evaluating the potential impact of this development on the air quality of the valley. Geothermal power generation may release a variety of gaseous substances to the atmosphere. The principal gas of concern is $\mathrm{H}_{2} \mathrm{~S}$, but other gaseous species such as $\mathrm{NH}_{3}, \mathrm{CO}_{2}, \mathrm{CH}_{4}, \mathrm{Rn}$, and $\mathrm{Hg}$ may also be released. To evaluate this impact, the air quality group addressed the following tasks:

- Evaluate the valley's air quality prior to development.
- Characterize the valley's atmospheric transport properties.

- Characterize gaseous species in the geothermal fluids for estimation of potential power plant emissions.

- Model valley-wide air quality for predicting air quality impact of future geothermal power generation.

To carry out these tasks we established a multidisciplinary program that required the combined efforts of many investigators from several laboratories. We approached the first two tasks by operating a network of six fixed-location air quality and meteorological monitoring stations and using a mobile air quality laboratory for site-specific measurements. These were fielded and operated by 
personnel from the Lawrence Livermore Laboratory (LLL) with support from the Imperial County Air Pollution Control District. Each station gathered data on the concentrations of selected gaseous pollutants and airborne particulates. Investigators from the University of California at Davis and Rockwell International analyzed the particulate samples collected at these stations. The quality assurance efforts associated with the ambient-air gas analyses were performed by Rockwell International under contract with the U.S. Environmental Protection Agency (EPA) (Las Vegas) as well as by the State of California Air and Industrial Hygiene Laboratory and the California Air. Resources Board. The EPA also supplemented the program by making additional air quality measurements in specific areas. EG\&G (Santa Barbara) also measured concentrations of airborne gases and particulate matter. Evaluating the potential emissions of pollutants from future geothermal power plants used the talents of several investigators from the Battelle Pacific Northwest Laboratories and LLL. This involved measuring specific chemical species in the geothermal fluids. The final task was carried out at LLL by using these measurements to model atmospheric transport for the air quality impact predictions.

This report describes the measurement methodology, summarizes the results, and assesses the potential impact of specific geothermal development scenarios on air quality. For detailed descriptions of the baseline air quality and meteorological data see Ref. 1; the particulars of the air quality modeling and impact assessment are included in Ref. 2.

\section{AIR QUALITY AND METEOROLOGICAL MEASUREMENTS}

\section{METHODOLOGY}

To perform the first two tasks a network of six fixed-location air quality and meteorological monitoring stations were erected within the Imperial Valley. These were operated from December 1976 to April 1978 at the sites shown in Fig. 1. Sites were selected after considering the most likely geothermal source points, the expected levels of ambient air pollutants, the distribution of population centers, and meteorology. Table 1 describes the site of each of the six air quality stations. We had stations in each of the four known geothermal resource areas (KGRA) in the Imperial Valley: Salton Sea (Site 1), Heber (Site 3), East Mesa (Site 4), and Brawley (Site 6). Site 2, in the city of Imperial, gave information on a population center in the central section of the valley. Sites 1 and 5 are near the south end of the Salton Sea, to monitor the flow entering or exiting the north end of the valley (see Fig. 1). Similarly, Sites 3 and 4 were located near the southern end of the valley at the Heber and East Mesa KGRAs to monitor the flow of pollutants across the southern boundary.

Each station continuously measured $\mathrm{H}_{2} \mathrm{~S}, \mathrm{SO}_{2}$, $\mathrm{O}_{3}, \mathrm{CO}_{2}$, and particulate concentrations; three stations were equipped to measure $\mathrm{NO}$ and $\mathrm{NO}_{\mathrm{x}}$ levels. Also included were periodic measurements of $\mathrm{Hg}$

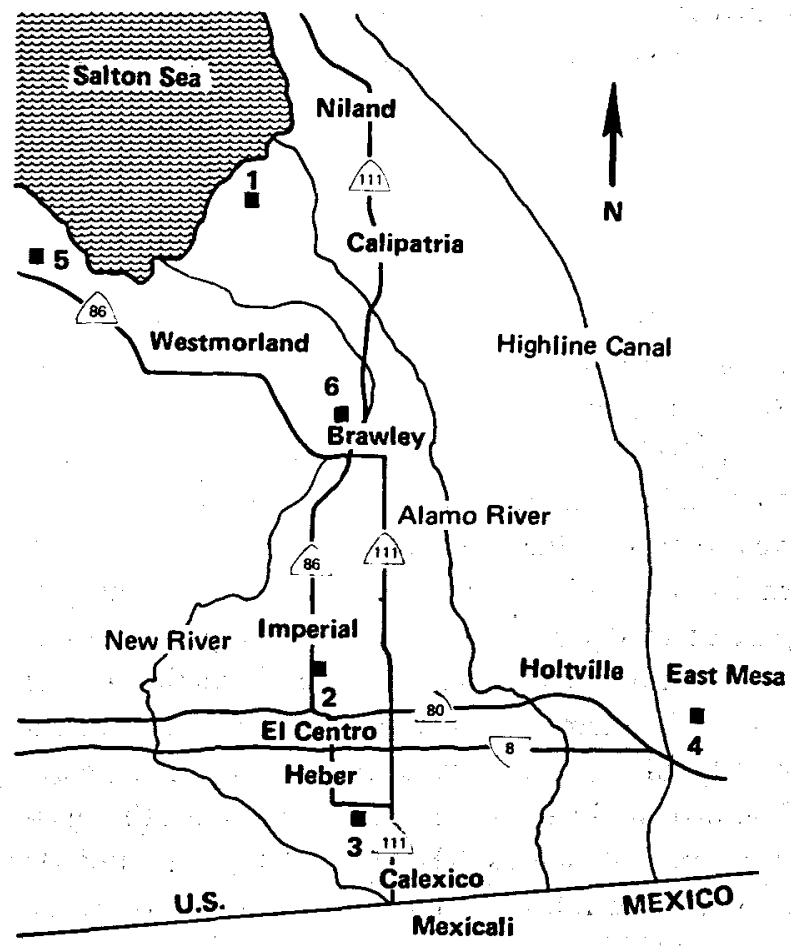

FIG. 1. Locations of air quality monitoring stations in the Imperial Valley. 
TABLE 1. Air quality station identification and location data.

\begin{tabular}{|c|c|c|}
\hline $\begin{array}{l}\text { Station } \\
\text { number }\end{array}$ & $\begin{array}{l}\text { Station } \\
\text { name }\end{array}$ & Location \\
\hline 1 & Niland & $\begin{array}{l}\text { Reinjection well of San Diego Gas \& } \\
\text { Electric Co. (SDG\&E) facility }\end{array}$ \\
\hline 2 & Imperial & $\begin{array}{l}\text { Imperial Irrigation District } \\
\text { Headquarters }\end{array}$ \\
\hline 3 & $\begin{array}{l}\text { Heber } \\
\text { East Mesa }\end{array}$ & $\begin{array}{l}\text { Chevron and SDG\&E site south of Heber } \\
\text { Bureau of Reclamation Well 5-1 }\end{array}$ \\
\hline 5 & Elmore & Elmore Land Company property \\
\hline 6 & Brawley & Union Oil Kruger Well No. 1 \\
\hline
\end{tabular}

concentrations at each site; $R \mathbf{n}$ was measured at the Niland site. These pollutants were selected because $\mathrm{H}_{2} \mathrm{~S}, \mathrm{Hg},{ }^{,} \mathrm{Rn}$, and $\mathrm{CO}_{2}$ may be direct emissions from some geothermal power production cycles.

Hydrogen sulfide is of great concern because of its potential release rate and noxious odor. It oxidizes to $\mathrm{SO}_{2}$ in the atmosphere and it is possible that $\mathrm{O}_{3}$ and $\mathrm{NO}_{2}$ play a role in that conversion process. Particulates were analyzed for elemental constituents and sulfate levels because of the potential for an accidental release of geothermal fluids into the environment with attendant emissions into the atmosphere of particulates containing different trace materials. To characterize the valley's atmospheric transport properties, we measured wind velocity and temperature at each site. Wind direction fluctuations $\left(\sigma_{(1)}\right)$ were measured at the Heber site for estimating atmospheric stability. An acoustic sounder determined inversion heights.

At each site, the system for air quality and meteorological monitoring consisted of the airquality sensors and the data processing and recording systems, which were housed in an airconditioned trailer. Five of the sites were equipped with 10-m-high, instrumented, meteorological towers. The Heber site, No. 3, contained a 60-m tower, instrumented at two levels and erected by the San Diego Gas and Electric Company (SDG\&E) under Electric Power Research Institute (EPRI) funding. Table 2 lists the air quality and meteorological sensors used in the program. Figure 2 is a schematic diagram of a typical station. Ambient air is drawn in, at a height of $5 \mathrm{~m}$, through a glass and teflon sample train that leads to the air-quality instruments. The outputs from these instruments and from the meteorological sensors were fed into a digital data logging system that featured a dual

TABLE 2. Air quality and meteorological instrumentation used in a typical air quality station.

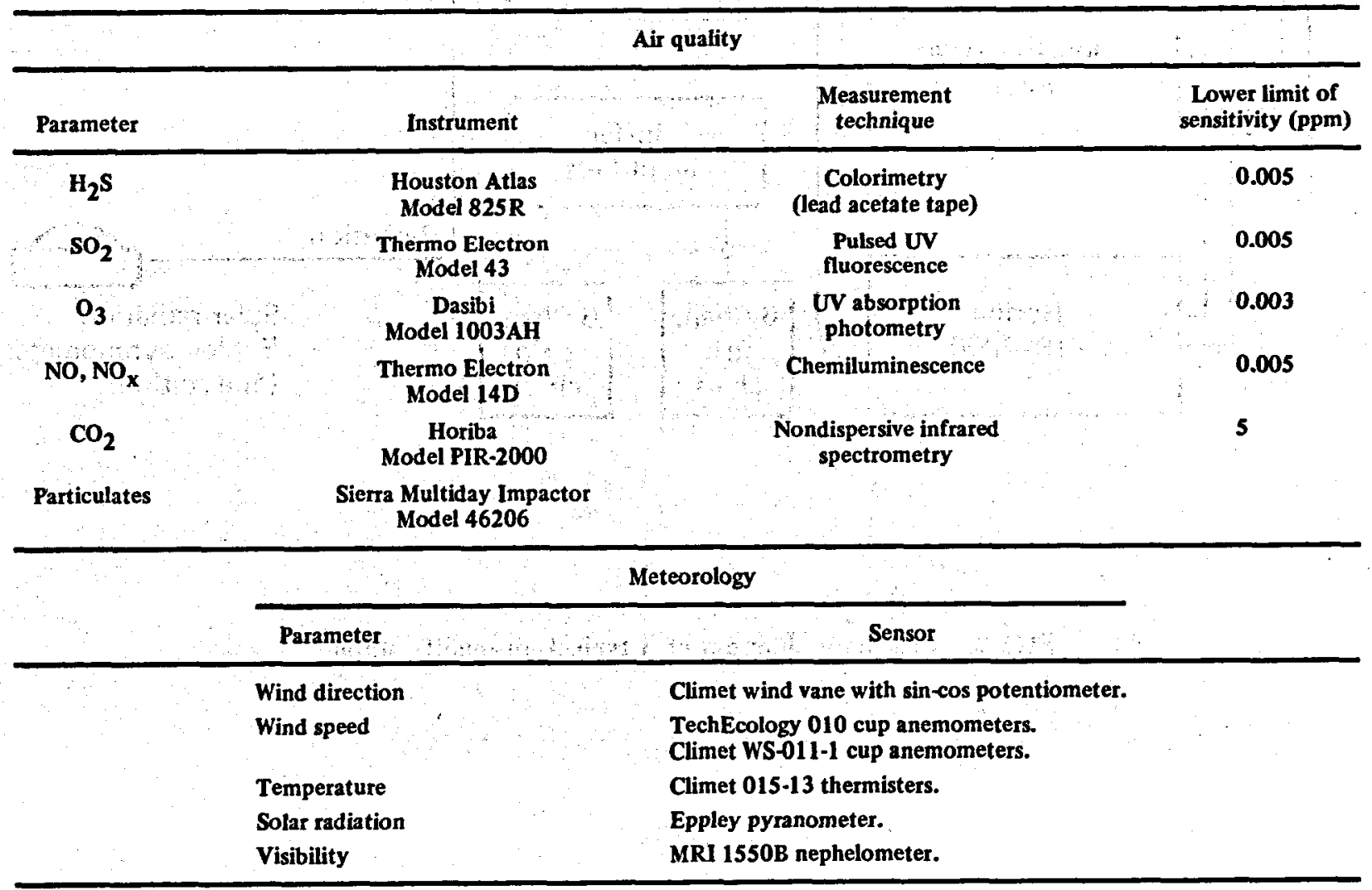




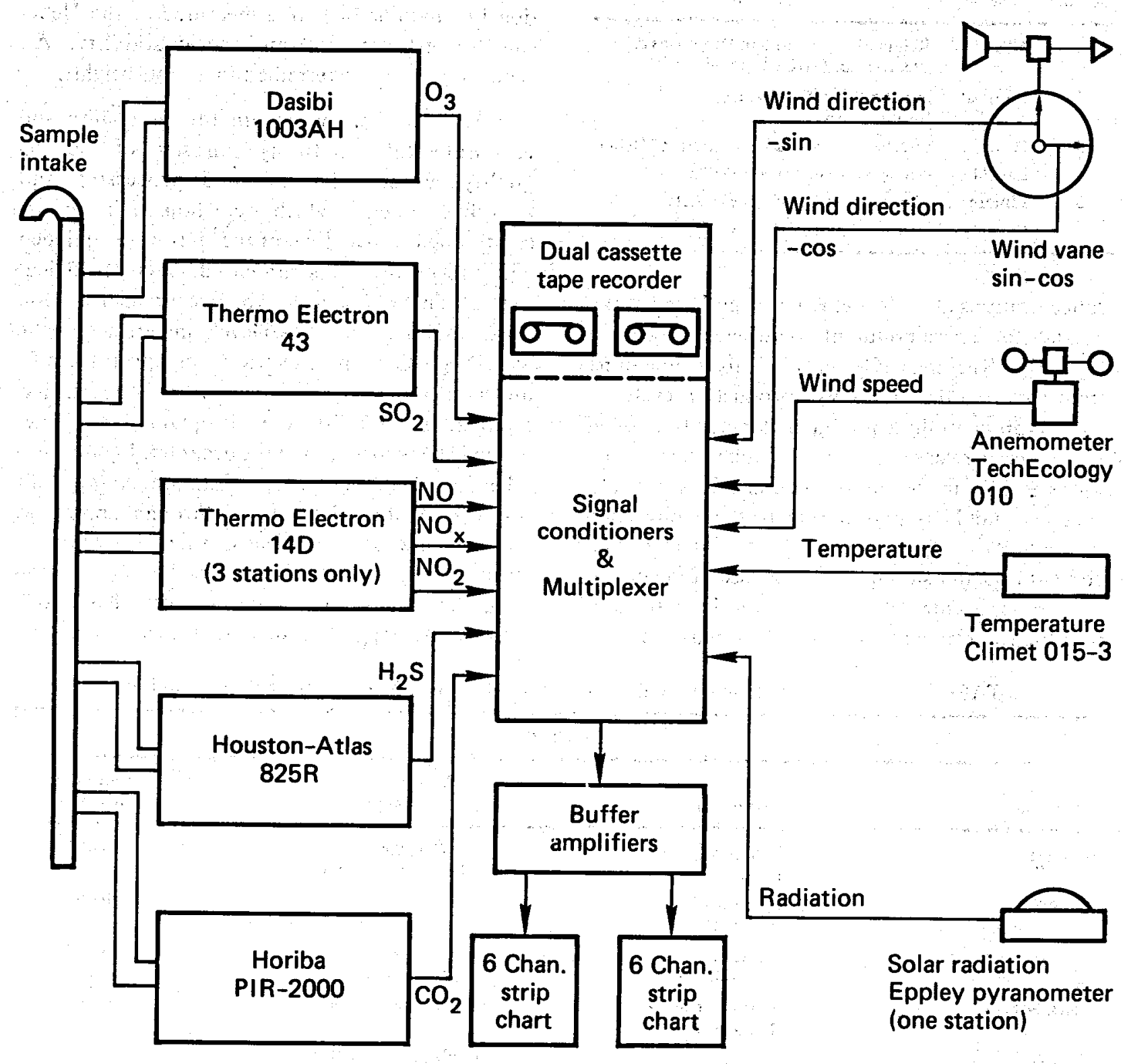

FIG. 2. Schematic diagram of a typical air-quality station. 
cassette-tape recording system. All signals were normally averaged over 15 -min periods. Peak values of all air-quality measurements were also recorded. Two 6-channel strip-chart recorders recorded data in selected channels. These backed up the tape systems and provided a means for evaluating instrument performance in the field. The tape cassettes were collected each week and sent to LLL where the data were extracted by a minicomputer and transferred to LLL's Octopus computer system for analysis.

A three-stage rotating drum impactor continuously sampled particulates at each site. The particles were collected on grease-coated mylar surfaces and back-up filters. The three size groups were 0.1 0.65 $\mu \mathrm{m}, 0.65-3.6 \mu \mathrm{m}$, and 3.6-20 $\mu \mathrm{m}$. The elemental analyses were performed by ion-induced $x$-ray fluorescence by the Air Quality Group at the University of California, Davis. In addition, a Hi-vol sampler collected particulates on a filter at each site for 24 hours per week. Rockwell International analyzed these filters for total sulfate and total mass loading.

Gaseous elemental mercury concentrations were determined by passing ambient air through a sampling tube filled with gold-coated glass beads in a manner similar to that used by Braman and Johnson. ${ }^{3}$ The mercury, which was absorbed onto the gold surfaces, was volatilized in the laboratory and subsequently analyzed by flameless atomic absorption techniques.

Radon-222 concentrations were measured by the two filter method described by Jacobi. ${ }^{4}$ This method involves drawing air through two filters placed at either end of a cylindrical chamber. The first filter removes all particulate radon daughter products but allows radon gas to enter the chamber. While in the chamber, a fraction of the radon decays to alpha-emitting daughter products that are deposited on the second filter. This filter is viewed by a zinc-sulfide phosphor-covered phototube thiat detects the alpha emissions from the daughter products. The output from the detector was then recorded by the station's digital data logging system.

To calibrate the air-quality instruments, we constructed a gas-calibration system that would deliver gas streams with known concentrations of test gases. This system operated on the dilution principle. Cylinders containing gases in relatively high concentrations ( 1 to $50 \mathrm{ppm}$ ) were diluted very accurately with clean air, referred to as zero air.

The zero-air system, shown in Fig. 3, was a major component of the calibrator. Ambient air was passed through a series of filters, converters, and reagent beds to remove trace gases in the air stream to produce the zero air. The concentrated span gas, whose concentration is accurately known, was blended with zero air in a teflon mixing chamber. The ratio of span gas to zero air could be accurately regulated by a combination of pressure and flow regulators and calibrated rotameters. Thus, it was possible to deliver a stream of air with a known concentration of pollutant gas; this air stream could be varied to calibrate all ranges of the instruments. For routine instrument calibration within the air quality stations, this system was mounted on the bed of a pickup truck. This let us deliver the calibration gas directly to the sample intake on the roof of the air quality station. The accuracy of the calibrator was independently verified on a periodic basis by the State of California Air and Industrial Hygiene Laboratory (AIHL), Berkeley, California.

Using this system we were able to calibrate all of the gas analyzers-with the exception of the ozone detector-at least twice each month. The primary ozone calibration was performed by comparing with an instrument calibrated by the California Air Resources Board; however, gas phase titration, based on ozone reactions with nitric oxide, was also used routinely for ozone calibrations. In addition, several calibration audits were performed by Rockwell International under US EPA (Las Vegas) contract as well as by the AIHL. The meteorology instruments were routinely checked each week; sensors were replaced as needed.

\section{RESULTS OF THE METEOROLOGICAL MEASUREMENTS}

The primary meteorological parameters of interest for characterizing the atmospheric transport properties over a region are wind velocity, atmospheric stability, and temperature inversion heights. The Imperial Valley is immediately east of the coastal mountain range, and is a part of California's southeastern desert. The area lies within the zone of prevailing westerlies and on the east side of the semipermanent high pressure area of the northeast Pacific Ocean. Thus, the prevailing nearsurface flow over the valley is from the southwest 


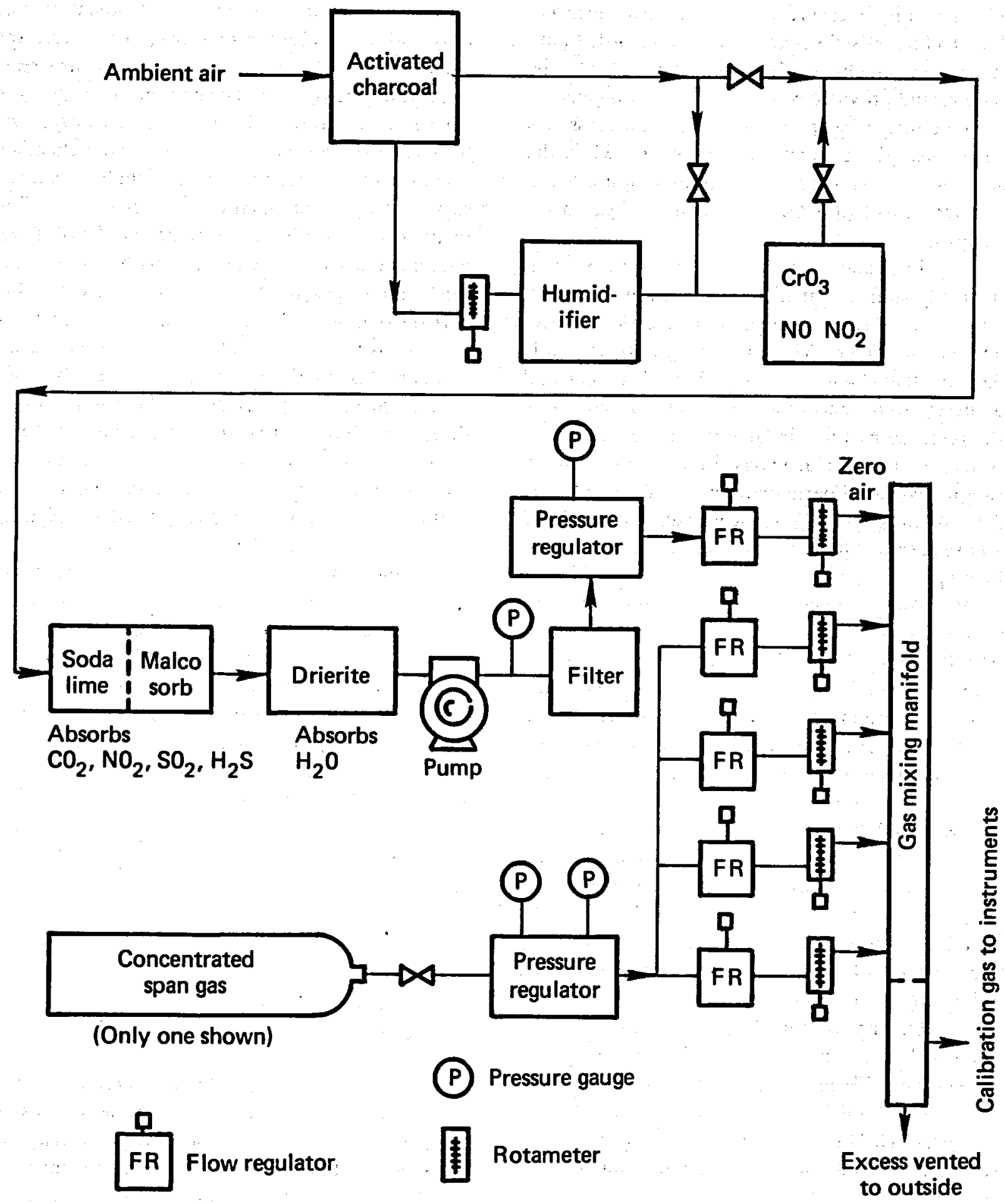

FIG. 3. A schematic diagram of the gas-calibration system used to calibrate the air quality instruments. 
through northwest during most of the year. This is illustrated in Fig. $4 \mathrm{a}$ by the wind roses derived from data collected at the six sites during January 1978. Individual differences are mainly due to upstream topographic effects caused by the coastal mountains. During the summer, intense surface heating occurs over the desert, producing a thermal low pressure region over the area. Average daily surface temperatures during July are typically about $34^{\circ} \mathrm{C}$. The dynamics of this thermal low pressure system produce an inflow toward the center of the thermal low. Hence, a southeasterly component is superimposed on the prevailing westerlies, as illustrated in Fig. 4b, by the wind roses from July 1977 . The near surface wind speeds are reasonably constant throughout the year; they averaged about $2 \mathrm{~m} / \mathrm{s}$ during January 1978 and $3 \mathrm{~m} / \mathrm{s}$ during July 1977 .

Atmospheric stability was estimated from the standard deviation of the horizontal wind direction fluctuations, $\sigma_{\theta}$, measured at a height of $10 \mathrm{~m}$ above the surface at the Heber site. These $\sigma_{\theta}$ values were used directly to determine the standard PasquillGifford stability categories. The frequency distributions of stability categories for the months of January 1978 and July 1977 are shown in Fig. S, During the winter, stability category $F$ is the most predominant, but $\mathrm{E}$ stability is nearly as frequent; during the summer, the slightly less stable
E category predominates. This agrees well with data published by the National Oceanic and Atmospheric Administration. ${ }^{5}$ The acoustic sounder at the Brawley site recorded temperature inversion heights. These data, in conjunction with differential temperature measurements on the $60 \mathrm{~m}$ tower at Heber, revealed a diurnal pattern that persisted throughout the year. A surface-based temperature inversion predominates at night. By mid-morning it is destroyed or rises above the instrument's range $(1 \mathrm{~km})$. The reverse process takes place during the early evening hours as the surface based inversion reforms.

\section{RESULTS OF THE AIR QUALITY MEASUREMENTS}

The ambient air concentrations of the gases were expected to be low because the Imperial Valley is a rural area with essentially no geothermal development. This is certainly borne out by the $\mathrm{H}_{2} \mathrm{~S}$ and $\mathrm{SO}_{2}$ concentrations measured at the six sites. These gases are of particular interest because of the potential $\mathrm{H}_{2} \mathrm{~S}$ emissions from power production and the subsequent oxidation to $\mathrm{SO}_{2}$ in the atmosphere. The distributions of $\mathrm{H}_{2} \mathrm{~S}$ concentrations measured at these sites are shown in Fig. 6. Since no seasonal
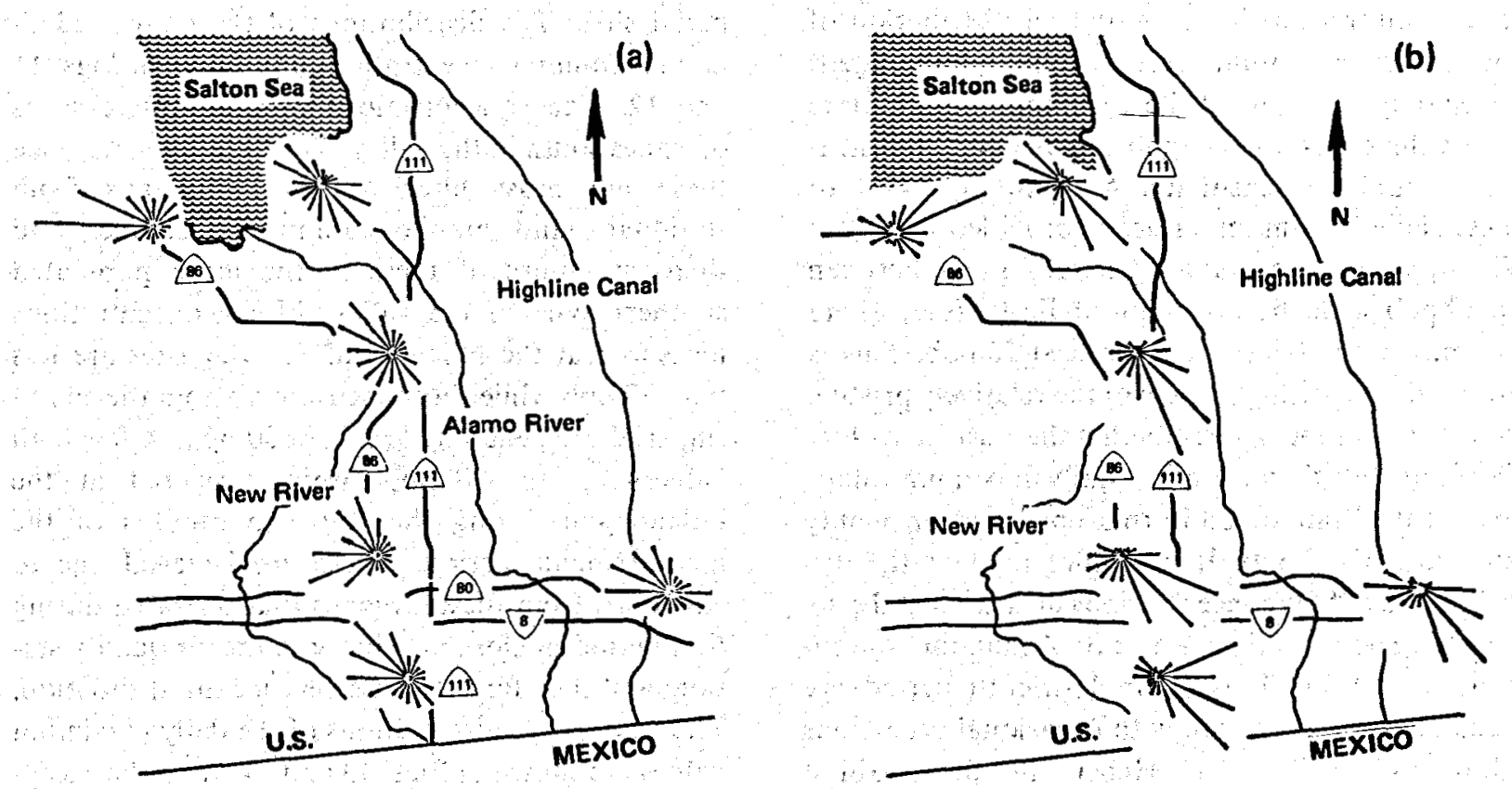

FIG. 4. Wind roses obtained at the air quality stations during January 1978 (a) and July 1977 (b). Bars point in the direction from which the wind is flowing. 

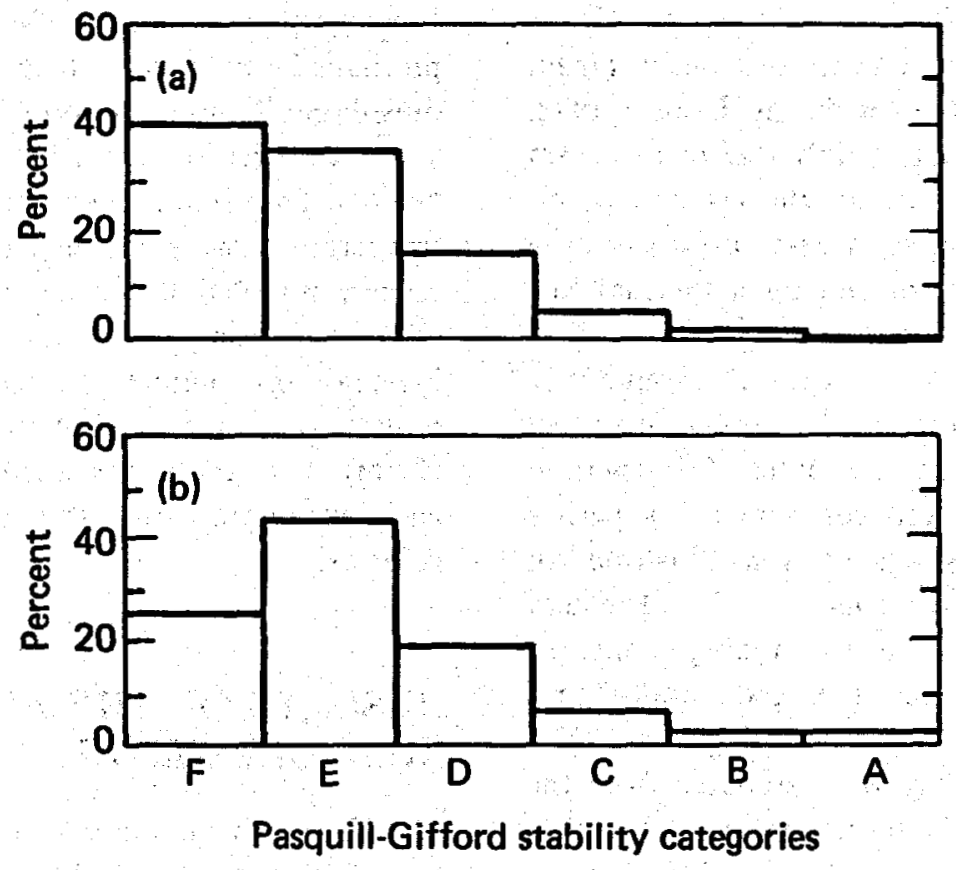

FIG. 5. Frequency distributions of Pasquill-Gifford stability categories measured at the Heber site during January 1978 (a) and July 1977 (b).

or diurnal fluctuations were observed, all data collected during the 15 -month measurements period are included in these figures. One readily notes that most values are less than $10 \mathrm{ppb}$, with a few excursions above this value. These excursions seem to occur randomly, and at least in some part may be due to agricultural fertilizers. A typical distribution of the daily maximum values (hourly averaged) measured at the Niland site is shown in Fig. 7. Note that values less than $5 \mathrm{ppb}$ are below the instrument's limit of sensitivity. A cumulative view of these daily maximum values is provided in Fig. 8. The upper extreme values generally range between 60-80 ppb with the exception at East Mesa, where the maximum values rarely exceed $30 \mathrm{ppb}$. This is not really surprising in view of the relatively pristine desert environment surrounding the East Mesa site. Generally less than $5 \%$ of the daily maximum values exceed the State of California one-hour air quality standard of $30 \mathrm{ppb}$. In a similar manner the distributions of $\mathrm{SO}_{2}$ concentrations measured at the six sites are shown in Figs. 9 and 10. Again, the concentrations measured over the 15 -month period are generally below $10 \mathrm{ppb}$, with occasional excursions above this value. The Heber site does exhibit somewhat higher concentrations relative to the other sites. This is probably due to its proximity to the principal population centers. However, even the upper range of the maximum values observed at Heber are significantly less than the California onehour-average $\mathrm{SO}_{2}$ air quality standard of $500 \mathrm{ppb}$.

Measurements of NO and $\mathrm{NO}_{\mathrm{x}}$ concentrations were only made at the Niland, Brawley, and Imperial sites. The distributions of the daily median and maximum concentrations are shown in Figs. 11 and 12. The concentrations generally increase as one goes south in the valley. This is reasonable since these are most likely due to emissions from stationary and mobile combustion sources and there are more of these in the more populated southern part of the valley. Most concentrations measured at the Niland and Brawley sites are less than $20 \mathrm{ppb}$ while those measured within the city of Imperial are generally less than $50 \mathrm{ppb}$. A few high values-up to $470 \mathrm{ppb}$-were measured at the Niland site during the last two months of the measurements period. These are believed due to emissions from diesel engines that operated during that period in close proximity to the air quality station, and therefore reflect a very localized situation. The cumulative distributions of the daily maximum values are shown in Figs. 13 and 14. With the exception of the elevated values at the Niland site, the California air quality standard of $250 \mathrm{ppb}$ (onehour average) was exceeded on less than $1 \%$ of the 


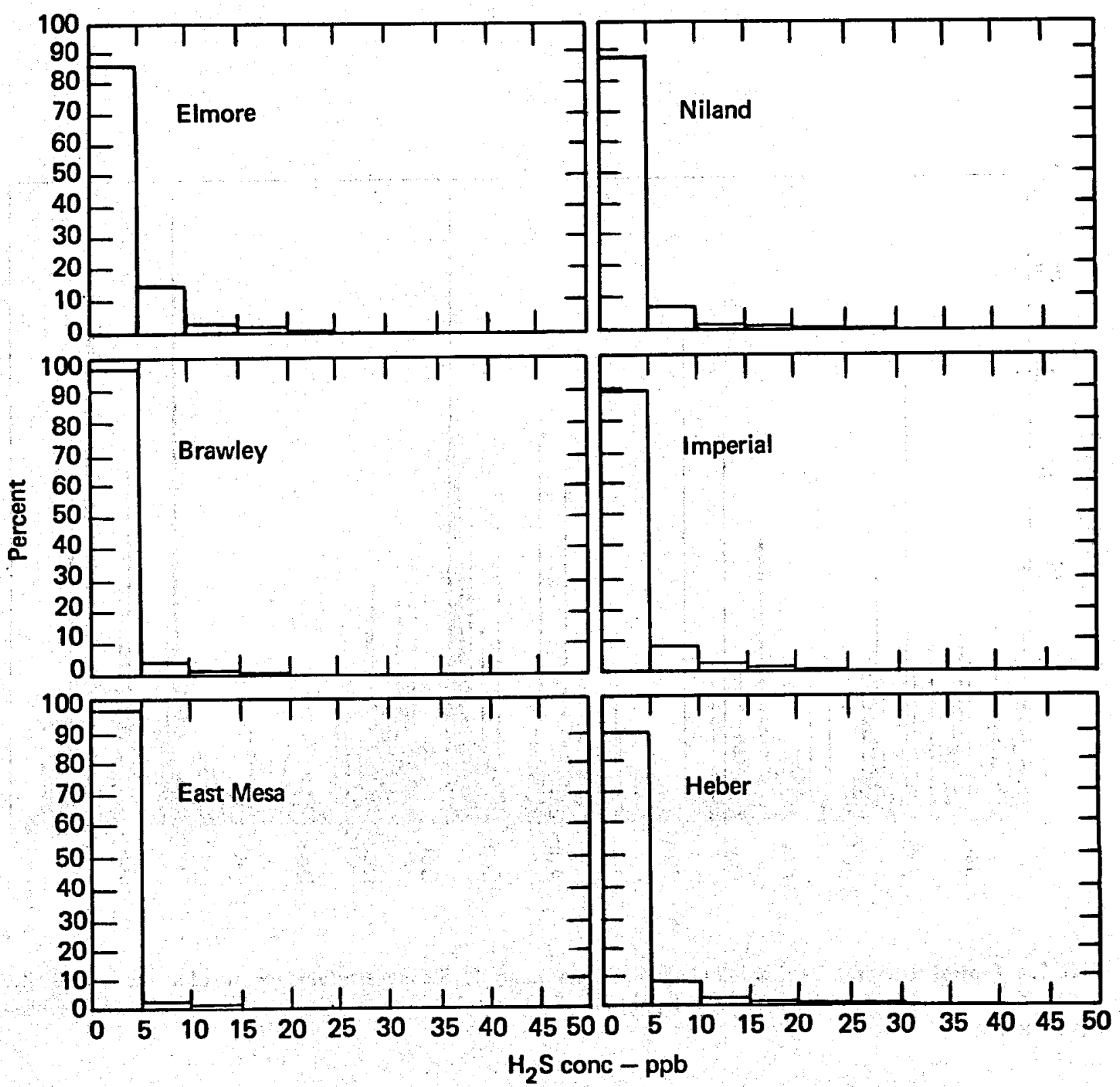

FIG. 6. Frequency distributions of the hourly averaged $\mathrm{H}_{2} \mathrm{~S}$ concentrations measured at the six air quality monitoring sites from December 1976 to April 1978. 


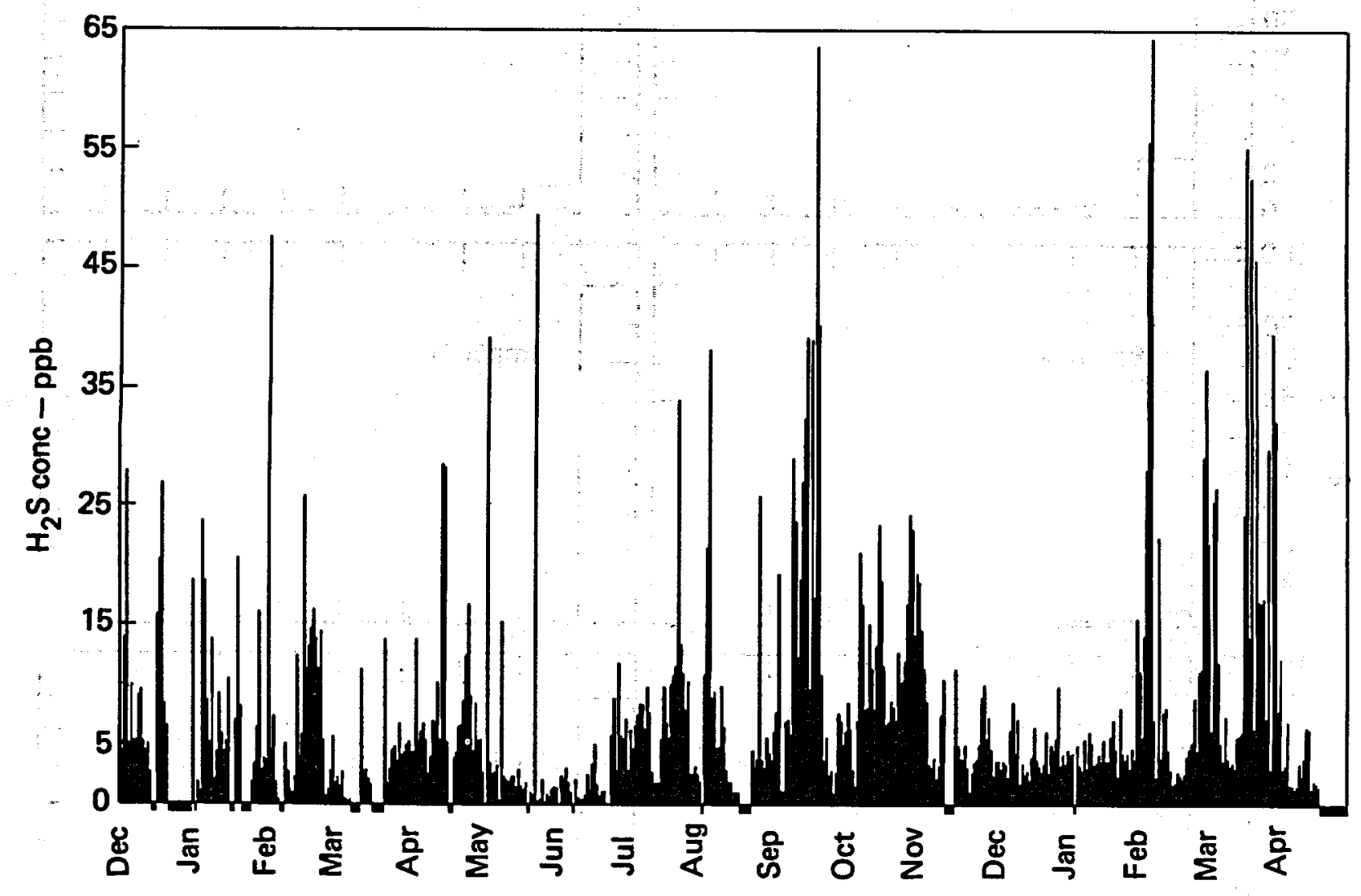

FIG. 7. Typical temporal distribution of the daily maximum $\mathrm{H}_{2} \mathrm{~S}$ concentrations measured at the Niland site. Note the minimum instrument sensitivity is $5 \mathrm{ppb}$. The tick marks below the zero concentration value denote missing values. 


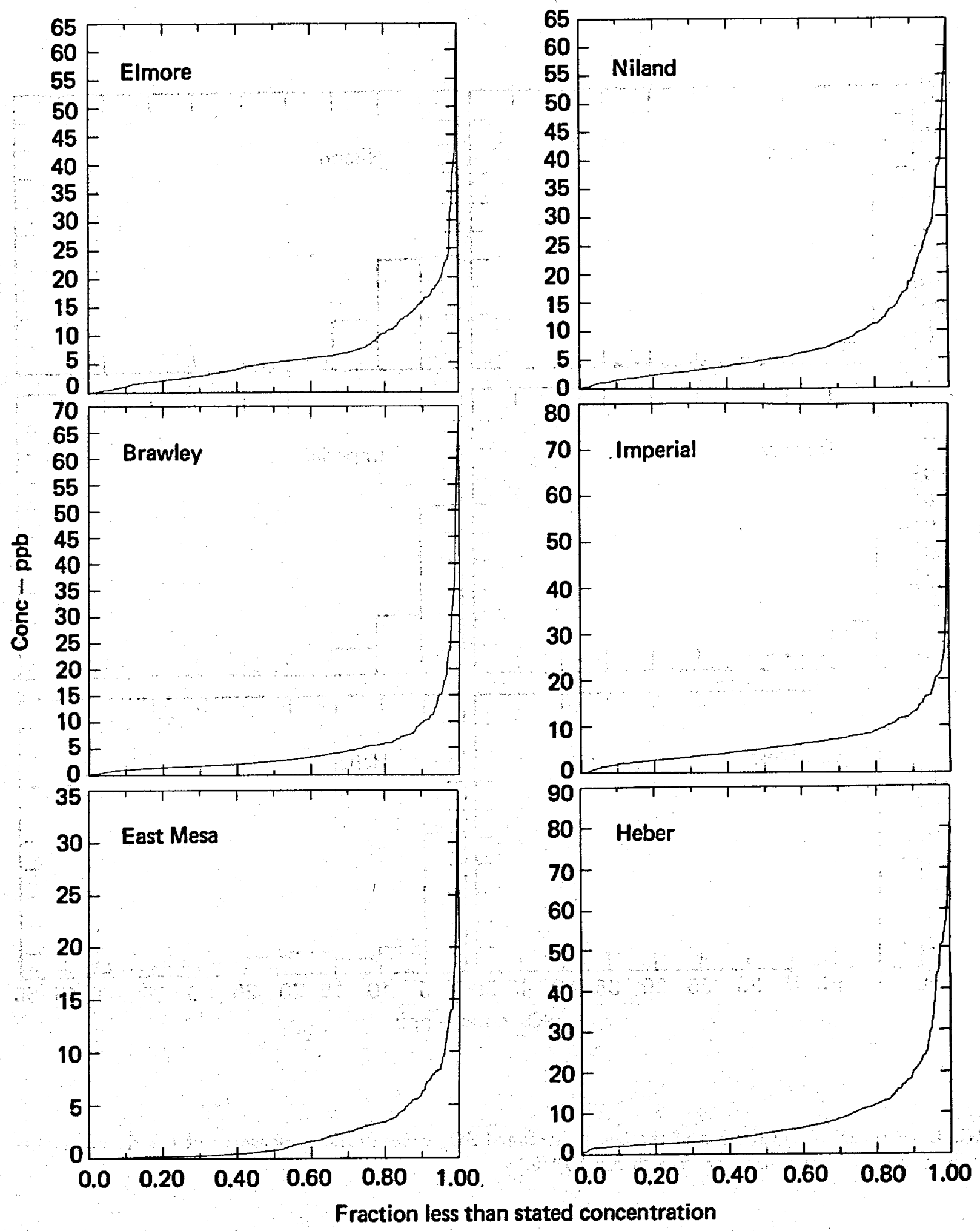

FIG. 8. Cumulative distributions of the hourly averaged, daily maximum $\mathrm{H}_{2} \mathrm{~S}$ concentrations measured at the six sites from December 1976 to April 1978. The State of California ambient air quality standard is 30 ppb. 


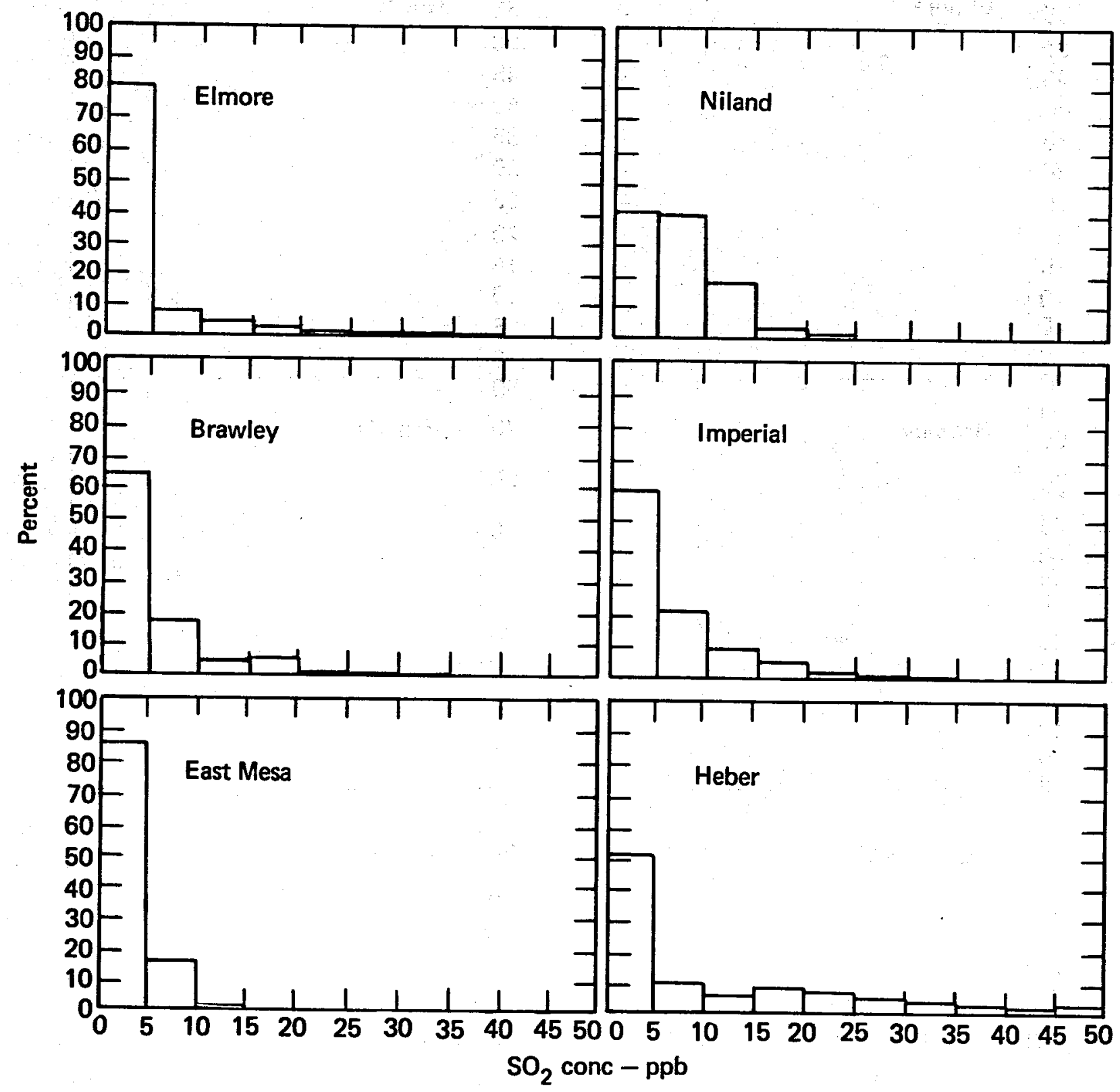

FIG. 9. Frequency distributions of the hourly averaged $\mathrm{SO}_{2}$ concentrations measured at the six air quality monitoring sites from December 1976 to April 1978. 


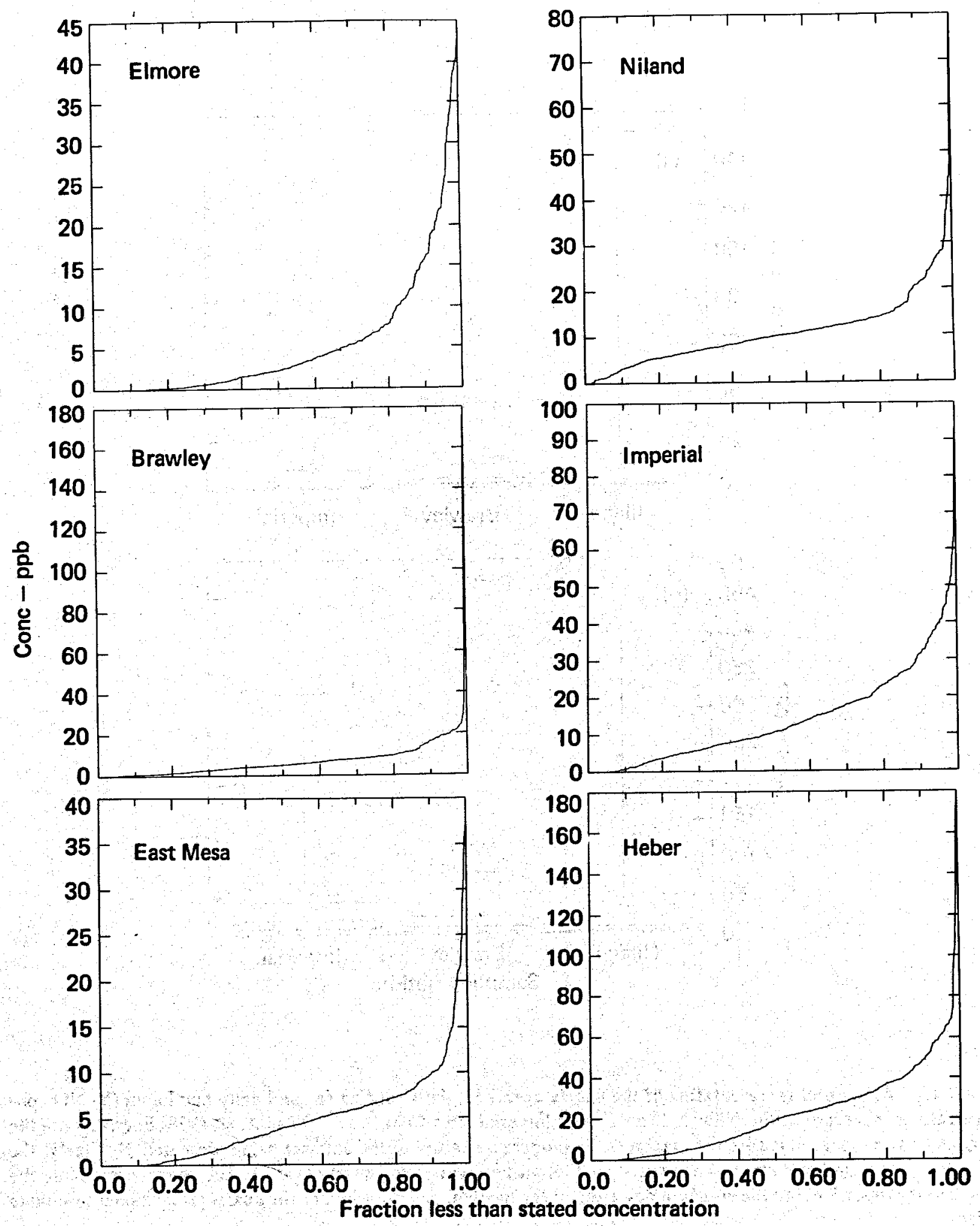

FIG. 10. Cumulative distributions of the hourly averaged, daily maximum $\mathrm{SO}_{2}$ concentrations measured at the six sites from December 1976 to April 1978. 

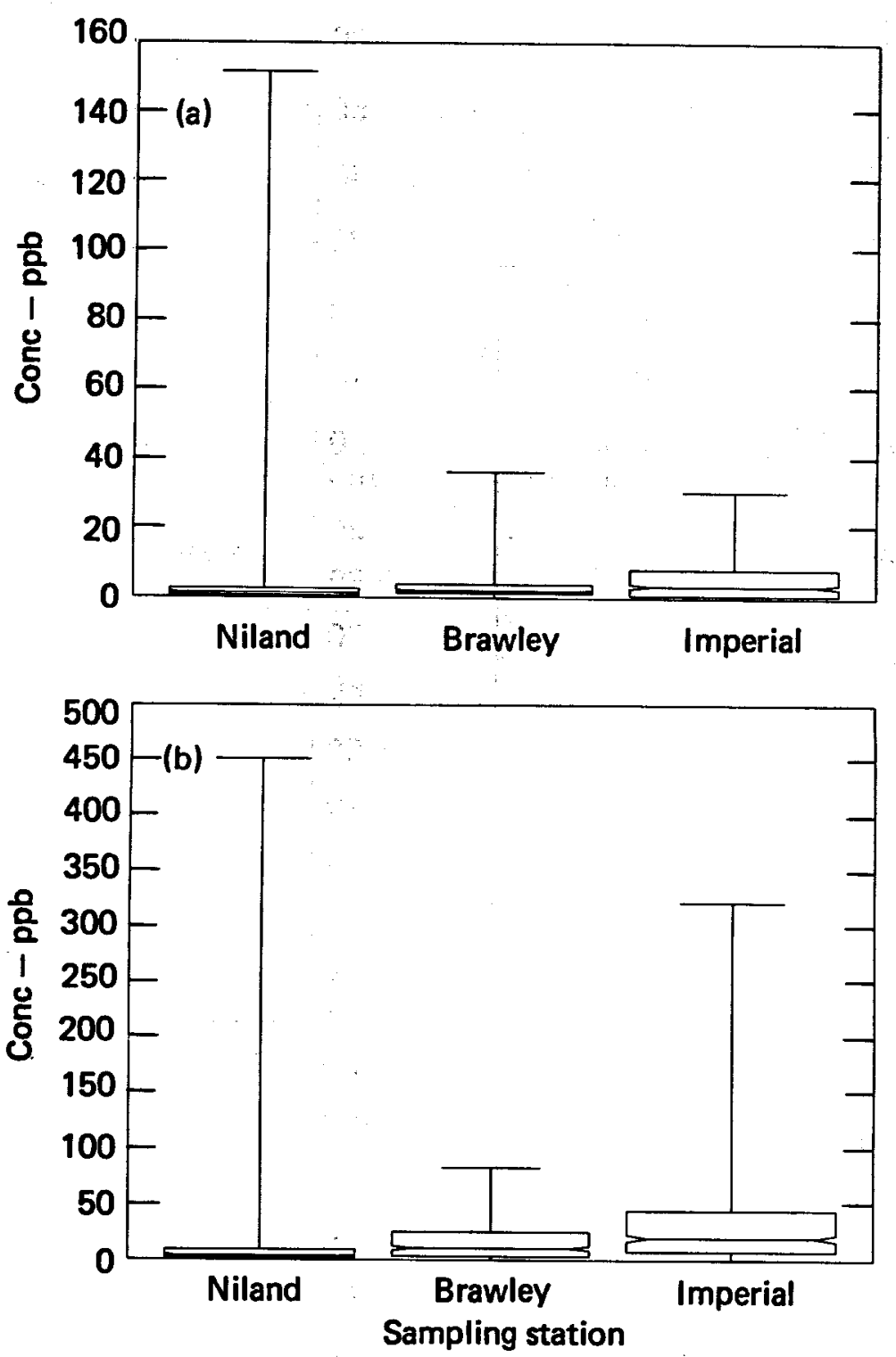

FIG. 11. A box plot representation of the hourly averaged, daily median (a) and daily maximum (b) NO concentrations measured at the Niland, Brawley and Imperial sites from May 1977 to April 1978. For each site the top and bottom bars illustrate the maximum and minimum values of the data set being presented. Similarly, the box top, waist, and bottom give the upper-quartile, median, and lower-quartile values. The notch surrounding the median is proportional to the standard deviation of the median, and the width of the box is proportional to sample size. 

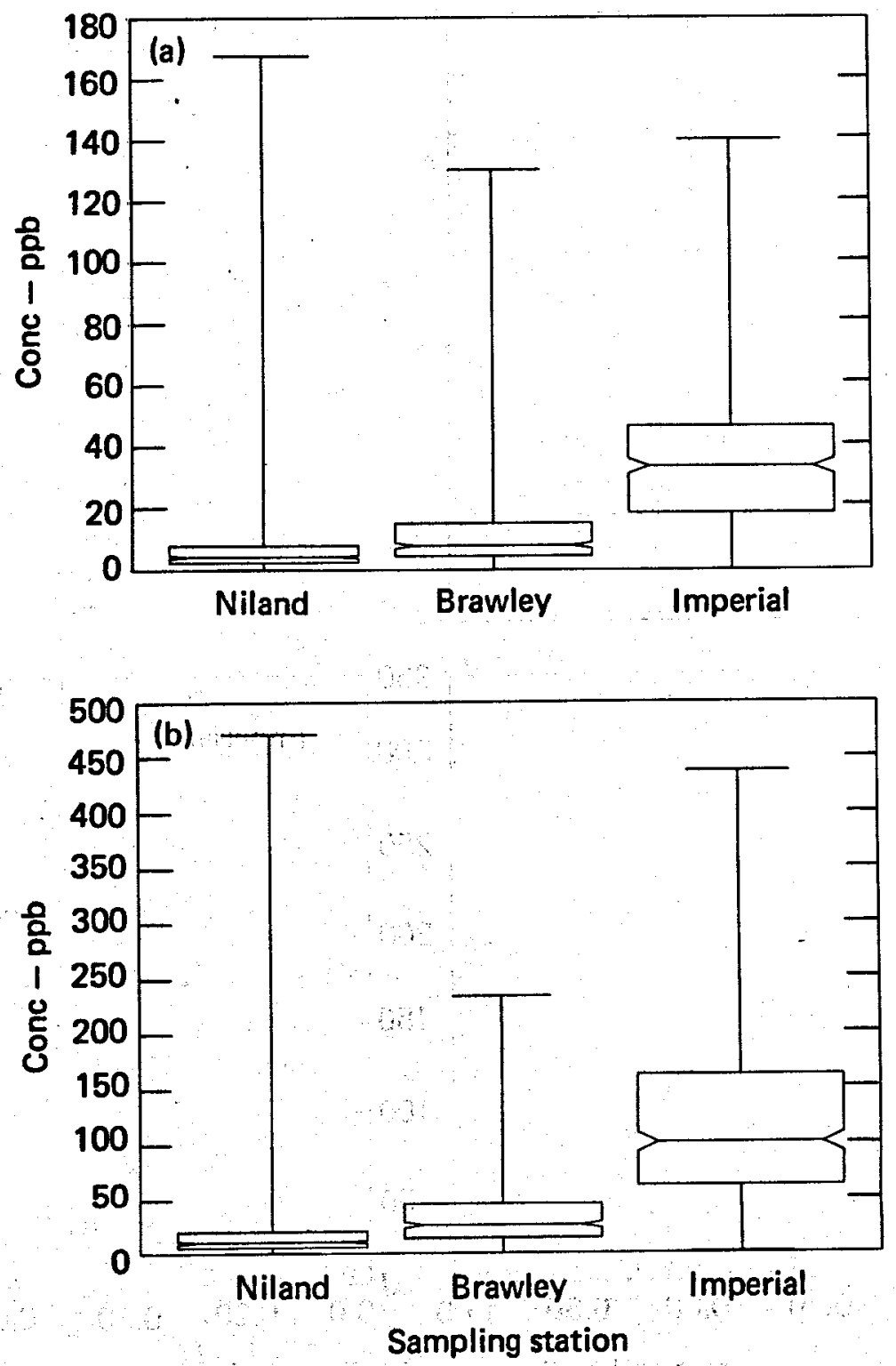

FIG. 12. The hourly averaged, daily median (a) and daily maximum (b) $\mathrm{NO}_{\mathbf{x}}$ concentrations measured by three air quality stations from May 1977 to April 1978. 

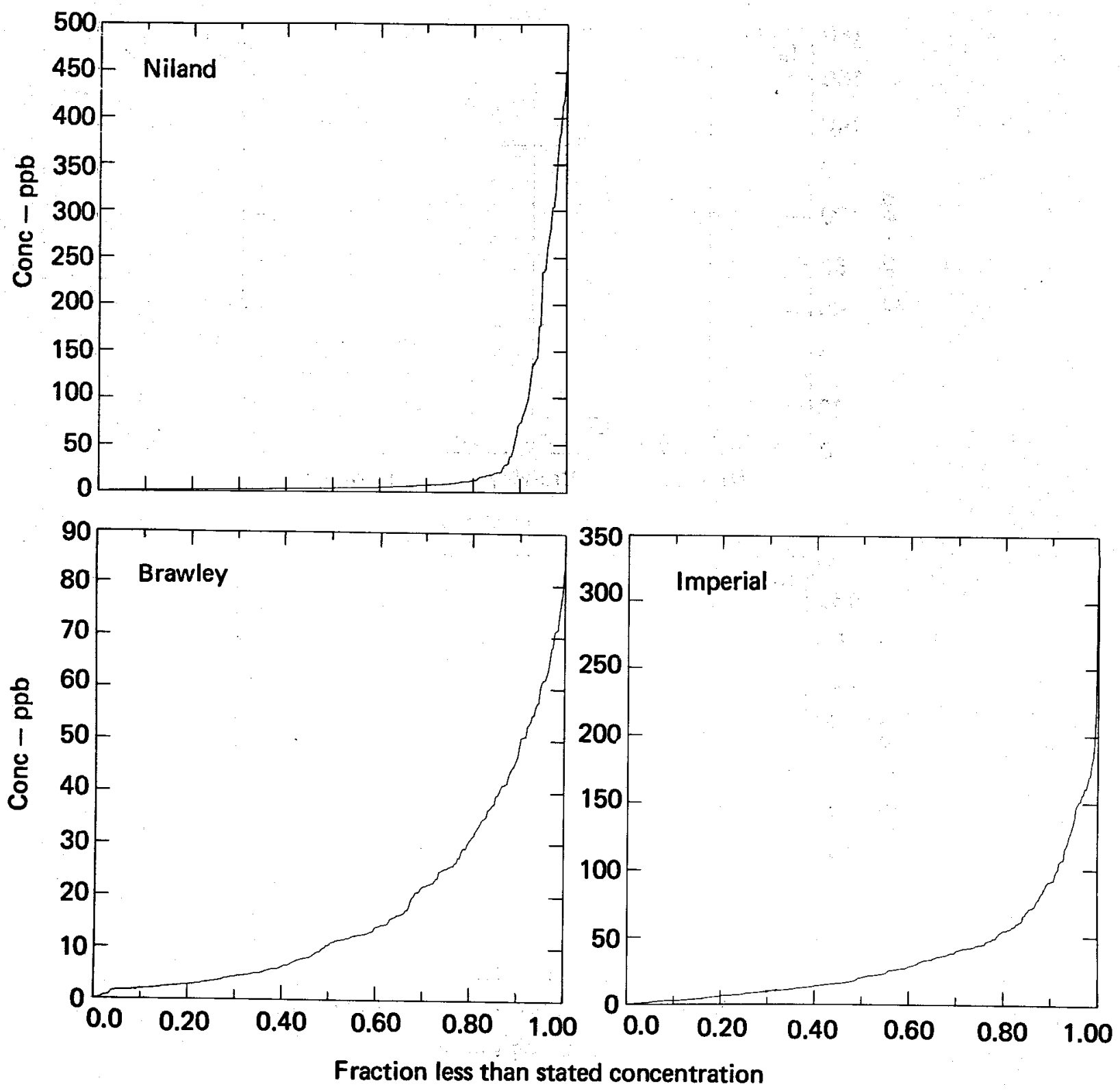

FIG. 13. Cumulative distributions of the hourly averaged, daily maximum NO concentrations measured at three air quality sites from May 1977 to April 1978. 

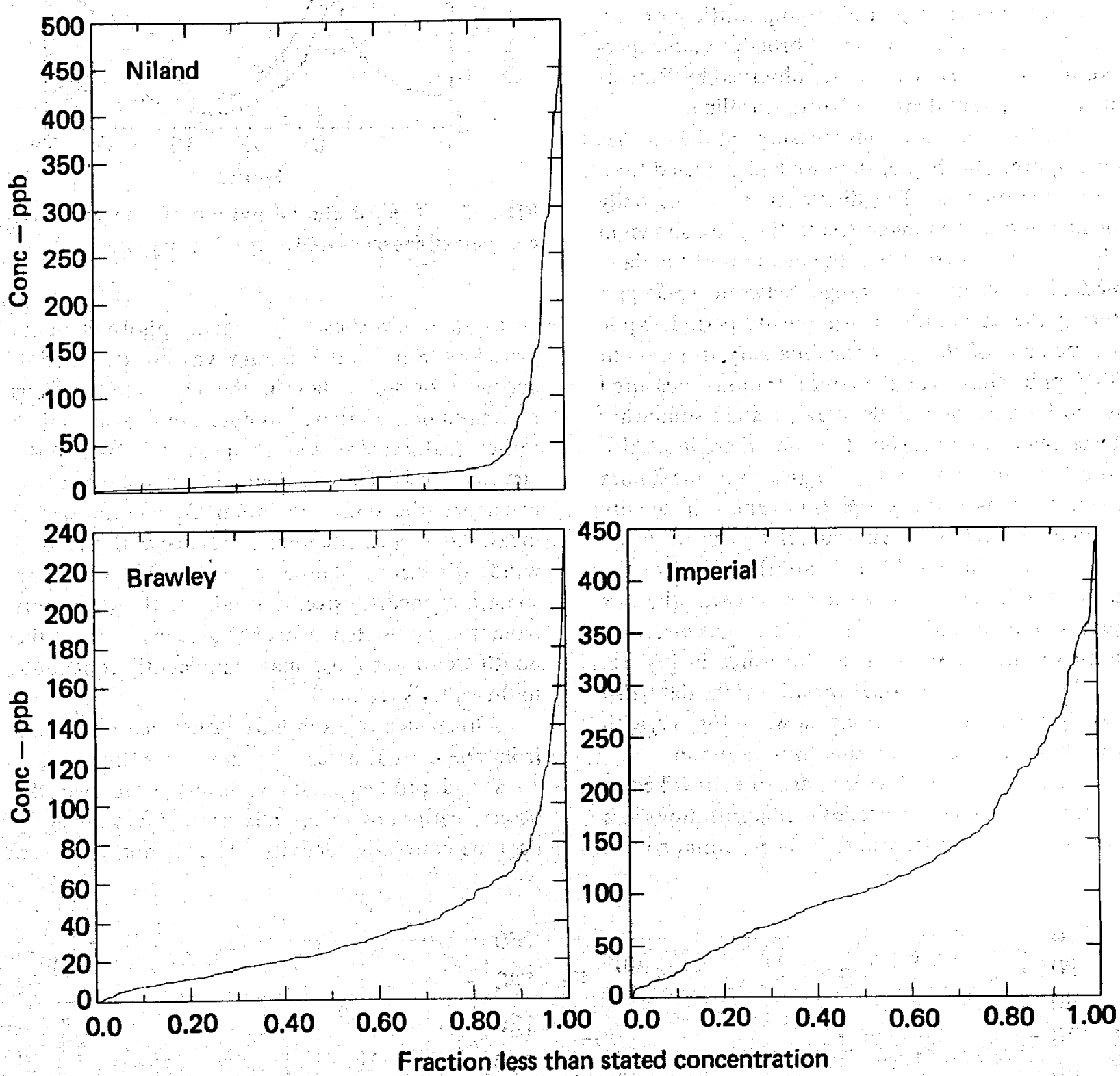

FIG. 14. Cumulative distributions of the hourly averaged, daily maximum $\mathrm{NO}_{\mathbf{x}}$ concentrations measured at three air quality sites from May 1977 to April 1978. 
days within the city of Imperial and was never exceeded at the Brawley site. The data display a diurnal pattern, shown in Fig. 15, with peaks that coincide with the morning and evening traffic patterns. The evening peak, however, is broader than expected, but is quite similar to that observed by Ripperton et al. ${ }^{6}$ in a rural area in North Carolina.

The $\mathrm{O}_{3}$ concentrations measured at the six sites were appreciably higher than we had expected for a rural environment. The distributions of the daily median and maximum concentrations are shown in Fig. 16. One observes that the medians of the daily median concentrations range between $15-35 \mathrm{ppb}$ during the 15-month measurements period, while the medians of the daily maxima vary from about 40-60 ppb. Note that the concentrations measured at the East Mesa and Brawley sites are somewhat lower than those measured at the other sites. Also note that the upper range of the daily maximum concentrations exceeds the California air quality standard of $100 \mathrm{ppb}$. The cumulative distribution plots, shown in Fig. 17, indicate that $2-8 \%$ of the daily maximum concentrations exceed the air quality standard. Most of these high concentrations occur during the summer, as illustrated in Fig. 18. In addition to the seasonal variations, the data also display the diurnal variations shown in Fig. 19, with a peak appearing during the mid-afternoon.

The principal factors that are often invoked to account for observed surface $\mathrm{O}_{3}$ concentrations in a specific region are transport from potential source

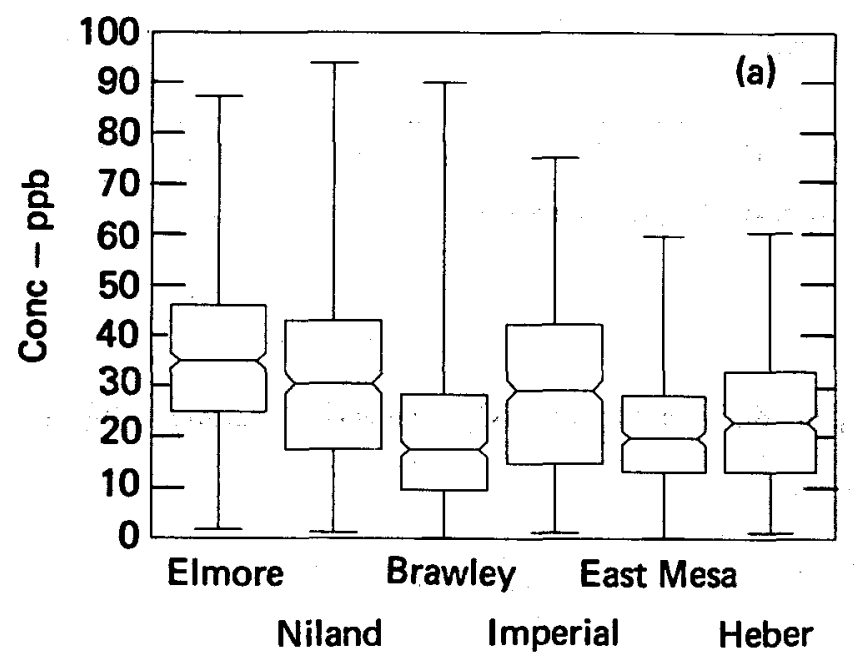

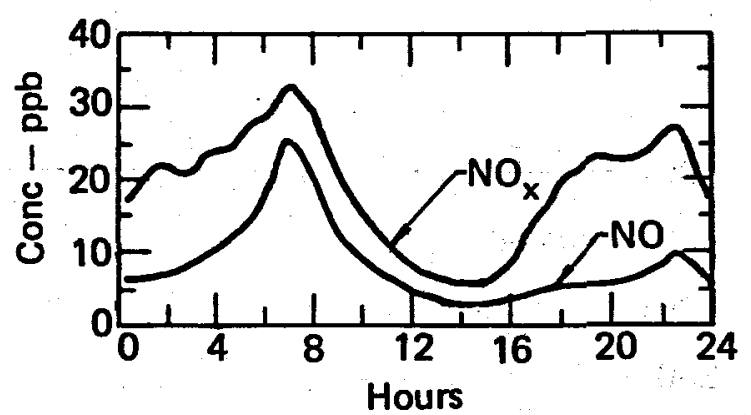

FIG. 15. Typical diurnal pattern of NO and NO concentrations measured at the Brawley site.

areas and synthesis by local photochemical processes. Since this program was not designed to account for anomalies in the $\mathrm{O}_{3}$ concentrations measured in the valley, this data can provide only a rather qualitative view of the possible causes of the elevated levels. To investigate the importance of $\mathrm{O}_{3}$ transport, the daily maximum $\mathrm{O}_{3}$ concentrations measured at each site were correlated with the local wind direction. These correlations, although somewhat inconclusive, did indicate that transport from the populated Mexicali area as well as the South Coast Air Basin may significantly contribute to the valley's $\mathrm{O}_{3}$ levels.

Other investigators have noted that pollutants from the coastal areas may move over the mountains and produce polluted layers aloft over the desert, with subsequent mixing to the surface by daytime convective activity. ${ }^{7}$ It does not, however,

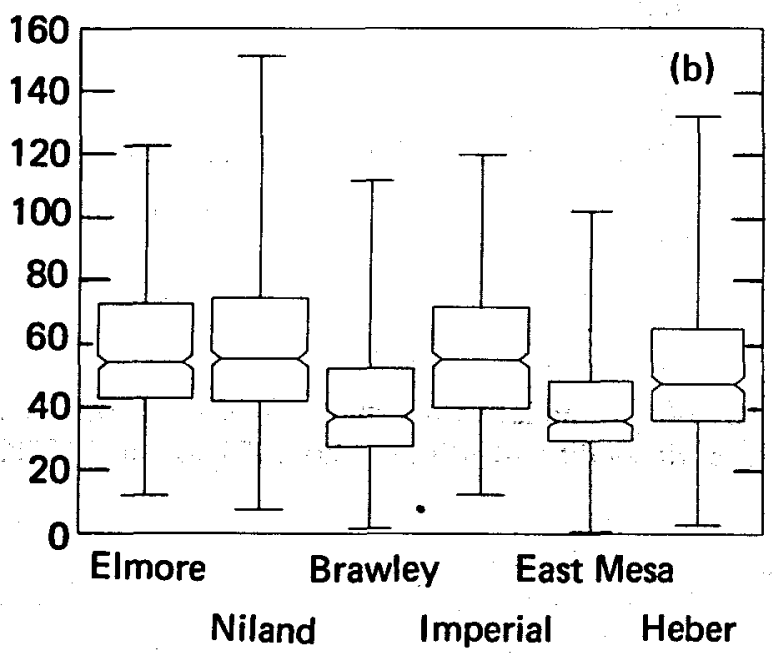

Sampling station

FIG. 16. The hourly averaged, daily median (a) and daily maximum (b) $\mathrm{O}_{3}$ concentrations measured at the six sites from December 1976 to April 1978. 

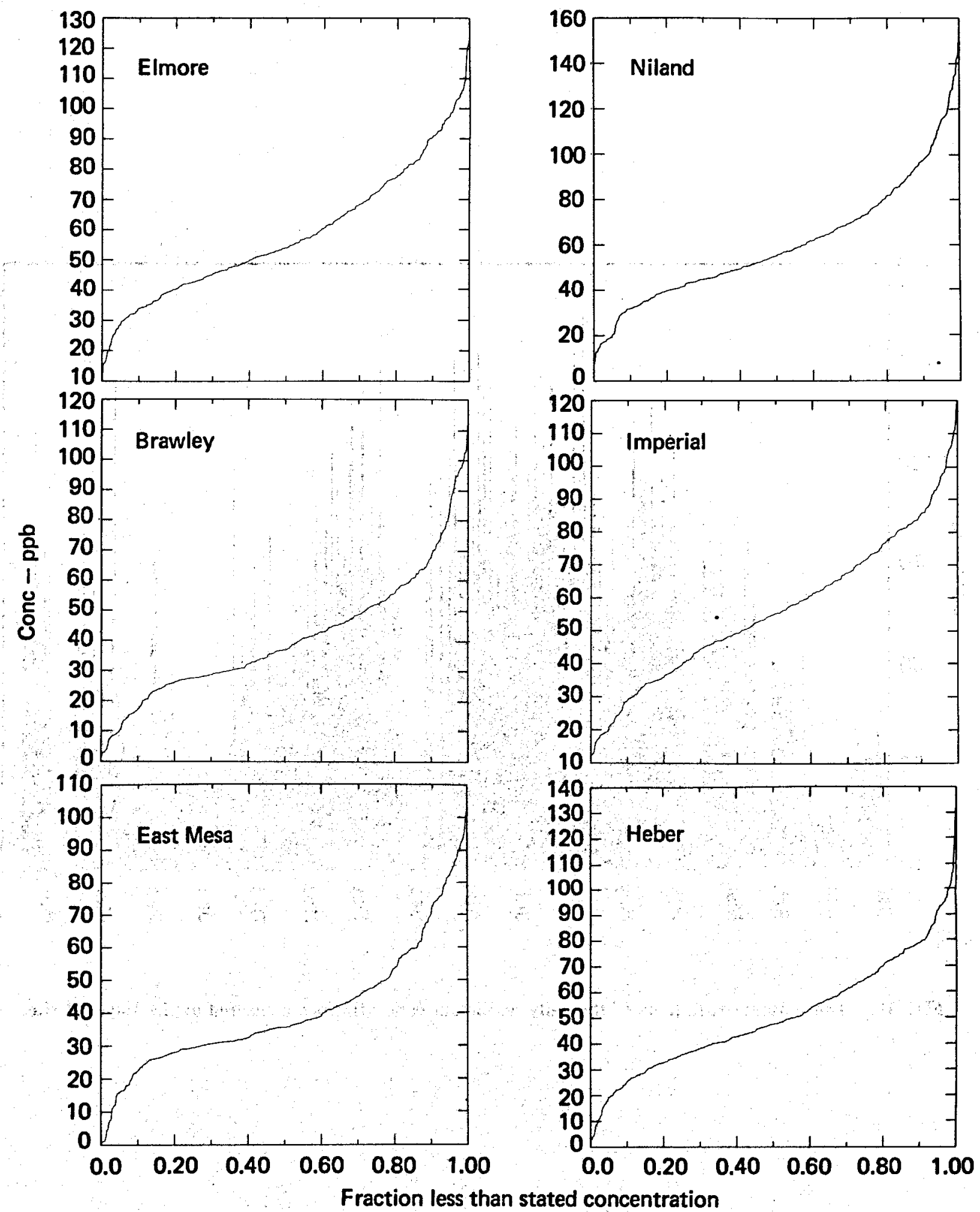

FIG. 17. Cumulative distributions of the hourly averaged, daily maximum $\mathrm{O}_{3}$ concentrations measured at the six sites from December 1976 to April 1978. The California air quality standard is $100 \mathrm{ppb}$. 


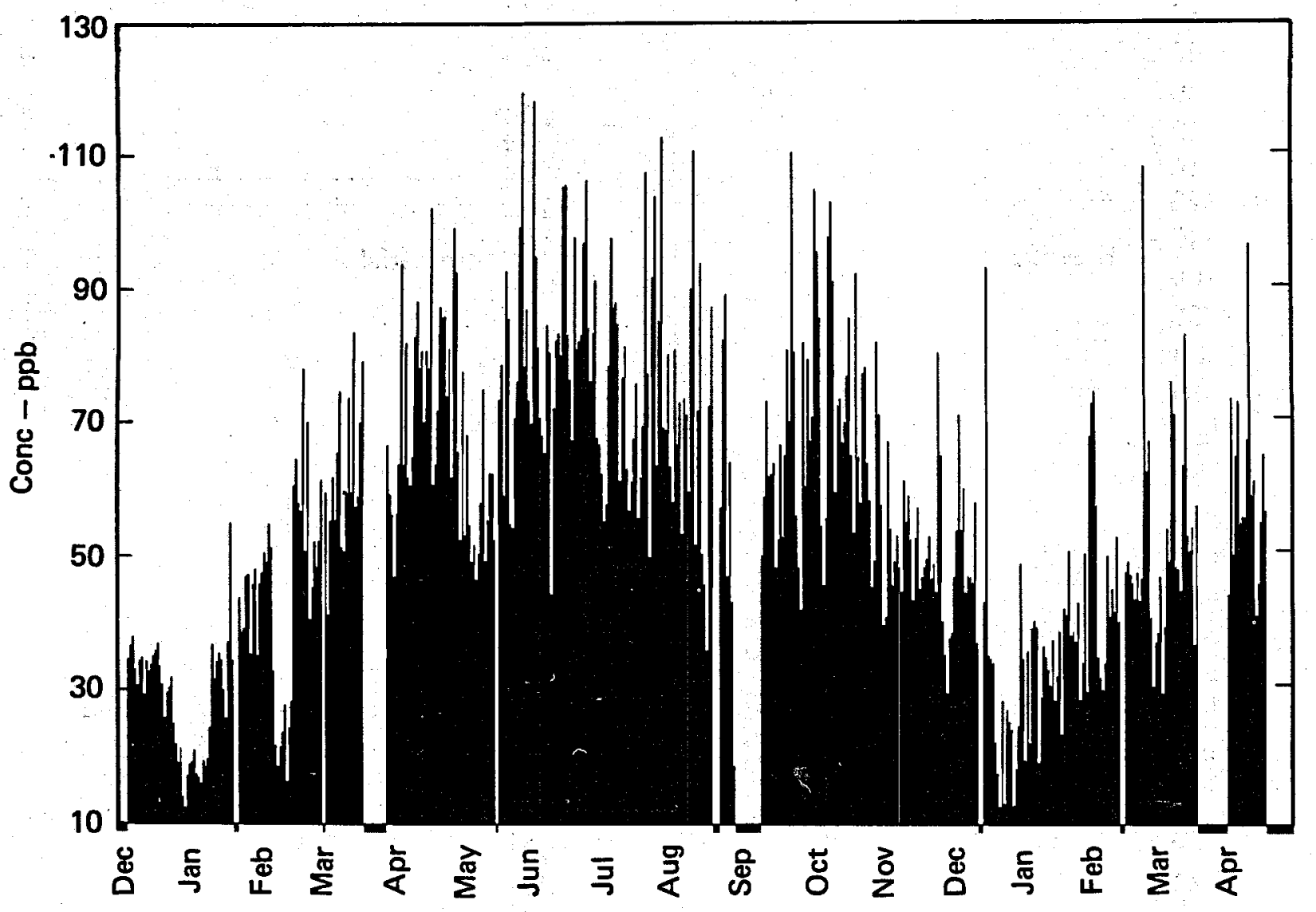

FIG. 18. The seasonal variations of the daily maximum concentrations measured at the Imperial site. 


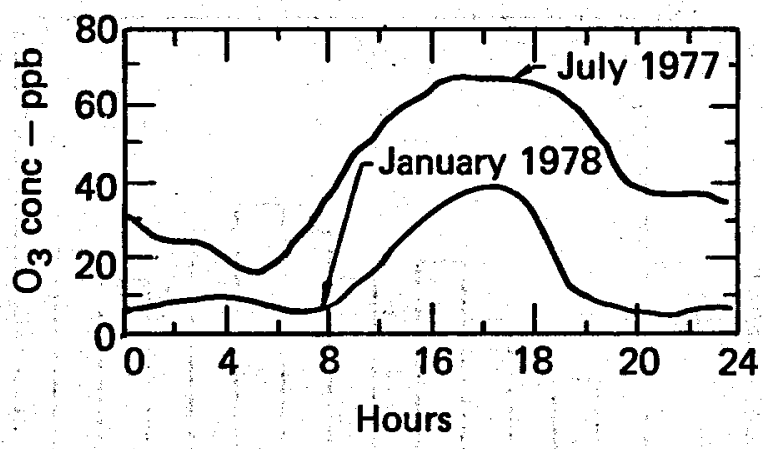

FIG. 19. Typical diurnal pattern of $\mathrm{O}_{3}$ concentrations measured at the Imperial site.

appear that mid-latitude injections of stratospheric $\mathrm{O}_{3}$ contribute significantly to the observed levels. This mechanism would require that maximum concentrations occur during the spring rather than during the summer. Furthermore, this mechanism produces relatively flat diurnal distributions ${ }^{8}$ quite unlike those observed. On the other hand, photochemical synthesis within the valley appears to present a viable explanation for the $\mathrm{O}_{3}$ observations. The principal processes that have been suggested for generating $\mathrm{O}_{3}$ in relatively unpolluted rural atmospheres involve complex reactions between methane, carbon monoxide, hydrogen oxides, and oxides of nitrogen in the presence of sunlight. It is interesting to note that the methane and carbon monoxide concentrations measured in the Imperial Valley by the California Air Resources Board, ${ }^{9}$ the hydroxyl radical concentrations measured by Davis over the southwestern U.S., ${ }^{10}$ and the oxides of nitrogen reported by this program do not differ greatly from those used by Chameides and Walker ${ }^{11}$ in their photochemical calculations that accounted for the general features of the $\mathrm{O}_{3}$ distributions observed at the EPA in Research Triangle Park, North Carolina. These features include the mid-afternoon peak in the diurnal pattern, the seasonal variations displaying the summer maximum, as well as the general level of $\mathrm{O}_{3}$ concentrations. Therefore; on the basis of these rather qualitative and somewhat inconclusive comments, it appears that the relatively high $\mathrm{O}_{3}$ concentrations may be due to a combination of transport of precursors from the Mexicali and South Coast Air Basin source areas as well as local photochemical production.

The $\mathrm{CO}_{2}$ concentrations measured at the six sites varied widely throughout the valley because of crop plant photosynthesis in the area. These variations are illustrated in Fig. 20, which shows the distributions of the hourly averaged daily median $\mathrm{CO}_{2}$ concentrations measured at the sites. The range of these median concentrations is almost $200 \mathrm{ppm}$ and possibly even more, since the upper range of the instrument was set at $450 \mathrm{ppm}$. Even the medians of

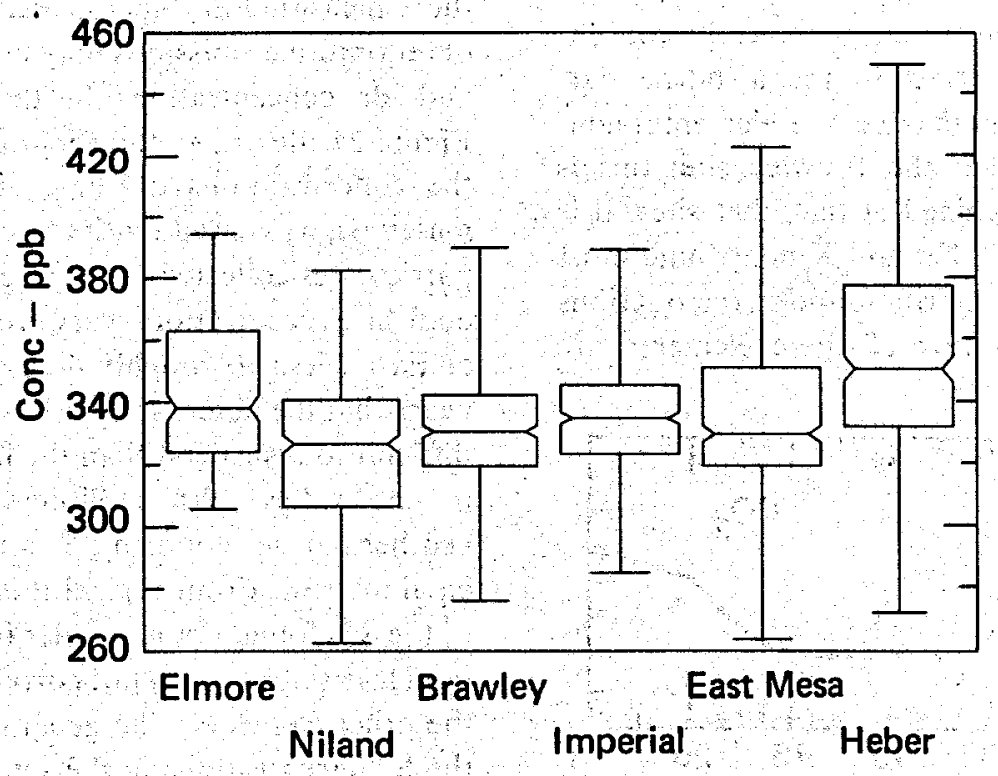

Sampling station

FIG. 20. The hourly averaged, daily median $\mathrm{CO}_{2}$ concentrations measured at the six sites from April 1977 to April 1978. 
these daily median values vary between 320 $340 \mathrm{ppm}$. The data reveal the typical diurnal pattern for agricultural lands, depicted in Fig. 21, described by Verma and Rosenberg. ${ }^{12}$ This pattern is linked with photosynthesis, which begins shortly after sunrise. The plants fix $\mathrm{CO}_{2}$ and there is an attendant sharp decrease in the atmospheric $\mathrm{CO}_{2}$ concentrations. Thereafter, the concentrations level off to a fairly constant value (about $300 \mathrm{ppm}$ ) until sunset, when photosynthesis stops. During the night the concentrations rise above the global average concentration (about $325 \mathrm{ppm}$ ) because $\mathrm{CO}_{2}$ is released by plant respiration and decay. Minimal atmospheric mixing during the night helps maintain the local concentration gradients.

The ${ }^{222} \mathrm{Rn}$ concentrations in the ambient air measured at the Niland site varied between $10 \mathrm{pCi} / \mathrm{m}^{3}$ to $1100 \mathrm{pCi} / \mathrm{m}^{3}$; the median value was $280 \mathrm{pCi} / \mathrm{m}^{3}$. The median concentration of gaseous elemental $\mathrm{Hg}$ measured periodically at the six sites was $3.0 \mathrm{ng} / \mathrm{m}^{3}$, the range was $1.2-9.8 \mathrm{ng} / \mathrm{m}^{3}$.

Particulates are a principal class of air pollutant in the Imperial Valley. This is illustrated by the data in Fig. 22, which show the monthly median concentrations of the total suspended particulates measured at the six sites by the Hi-vol samplers. Most values exceed the California 24-hour air quality standard of $100 \mu \mathrm{g} / \mathrm{m}^{3}$. The elemental analyses (conducted by UC-Davis) of the samples collected by the three-stage cascade impactors revealed a wealth of information about the concentrations of trace materials in the airborne particulates. Figure 23 summarizes the elemental concentrations measured at the Brawley site; this is typical of the data obtained at the other sites. It is evident that $\mathrm{Si}, \mathrm{Ca}, \mathrm{Al}, \mathrm{Fe}$, and $\mathrm{K}$ contribute most of the mass and are primarily found in the fractions of larger size. The ratios of these elements are

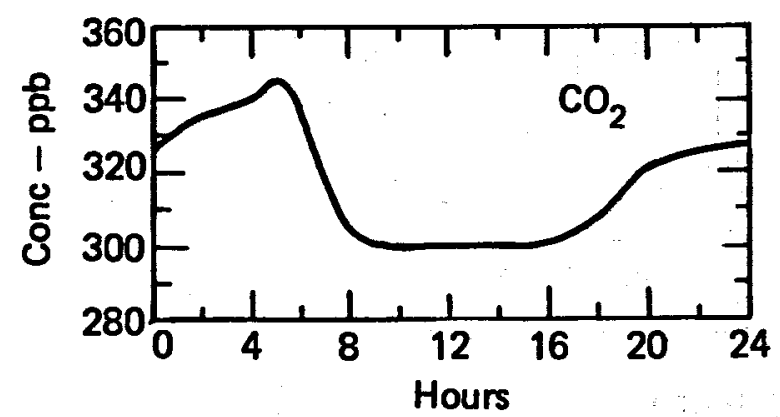

FIG. 21. A typical diurnal pattern of $\mathrm{CO}_{2}$ concentrations measured at the Brawley site.

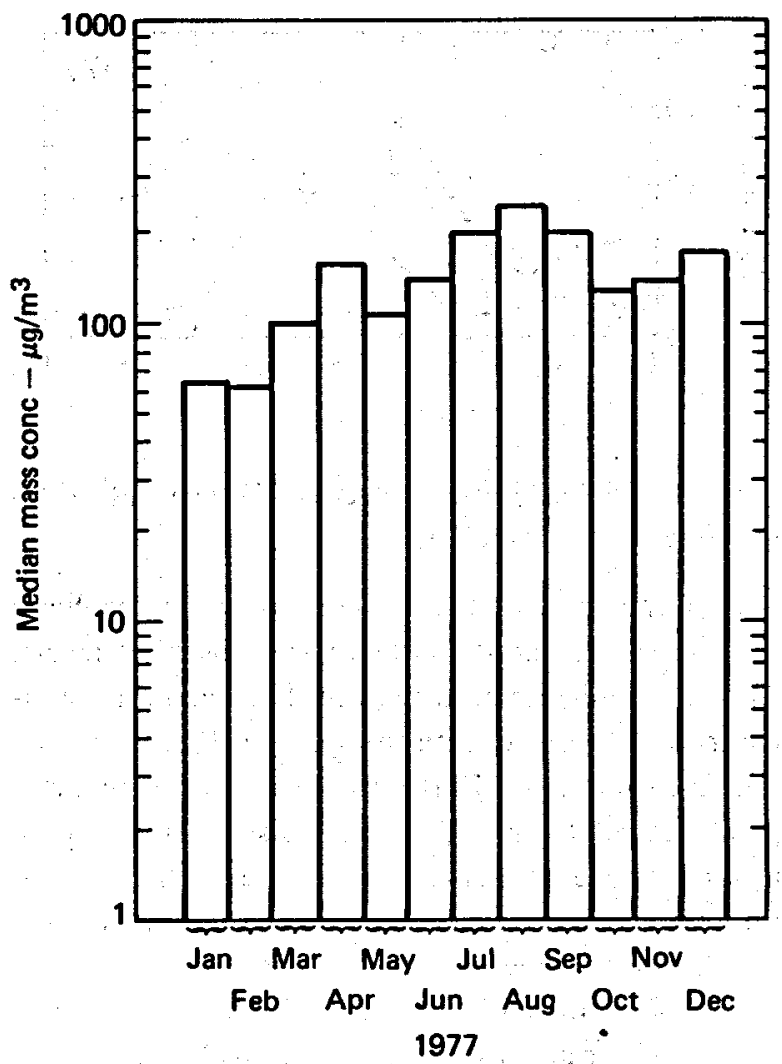

FIG. 22. The median mass concentrations of the total suspended particulates collected at the six sites during 1977. The data are averaged over 24-hour periods.

relatively constant with time and are similar to those measured in Imperial Valley soils. The impact of automotive emissions may be indicated by the $\mathrm{Pb}$ and $\mathrm{Br}$ concentrations in the smaller fractions. Figure 24 illustrates the geographical variability in the concentrations of these airborne soil-derived materials, as viewed by the $\mathrm{Si}$ concentrations in the particulates collected in the large fractions. The median $\mathrm{Si}$ concentrations vary from about $1.5 \mu \mathrm{g} / \mathrm{m}^{3}$ at East Mesa to roughly $4 \mu \mathrm{g} / \mathrm{m}^{3}$ at Heber. It appears that the desert soils at East Mesa may be more difficult to resuspend than the fine agricultural soils in the valley. When discussing the impact of geothermal development, $S$ is the element of principal interest. From Fig. 23 it is apparent that most of the $S$ is found in the smaller fractions. Its origin is not clear since it does not correlate well with any of the other elements. The geographical variability of the $\mathrm{S}$ concentrations in the small fraction is shown in Fig. 25. The median concentrations vary between 0.3 and $0.6 \mu \mathrm{g} / \mathrm{m}^{3}$. If one assumes that $S$ is present as $\mathrm{SO}_{4}$, then the mass of $\mathrm{SO}_{4}$ in all three sizefractions is calculated by multiplying the total $S$ 

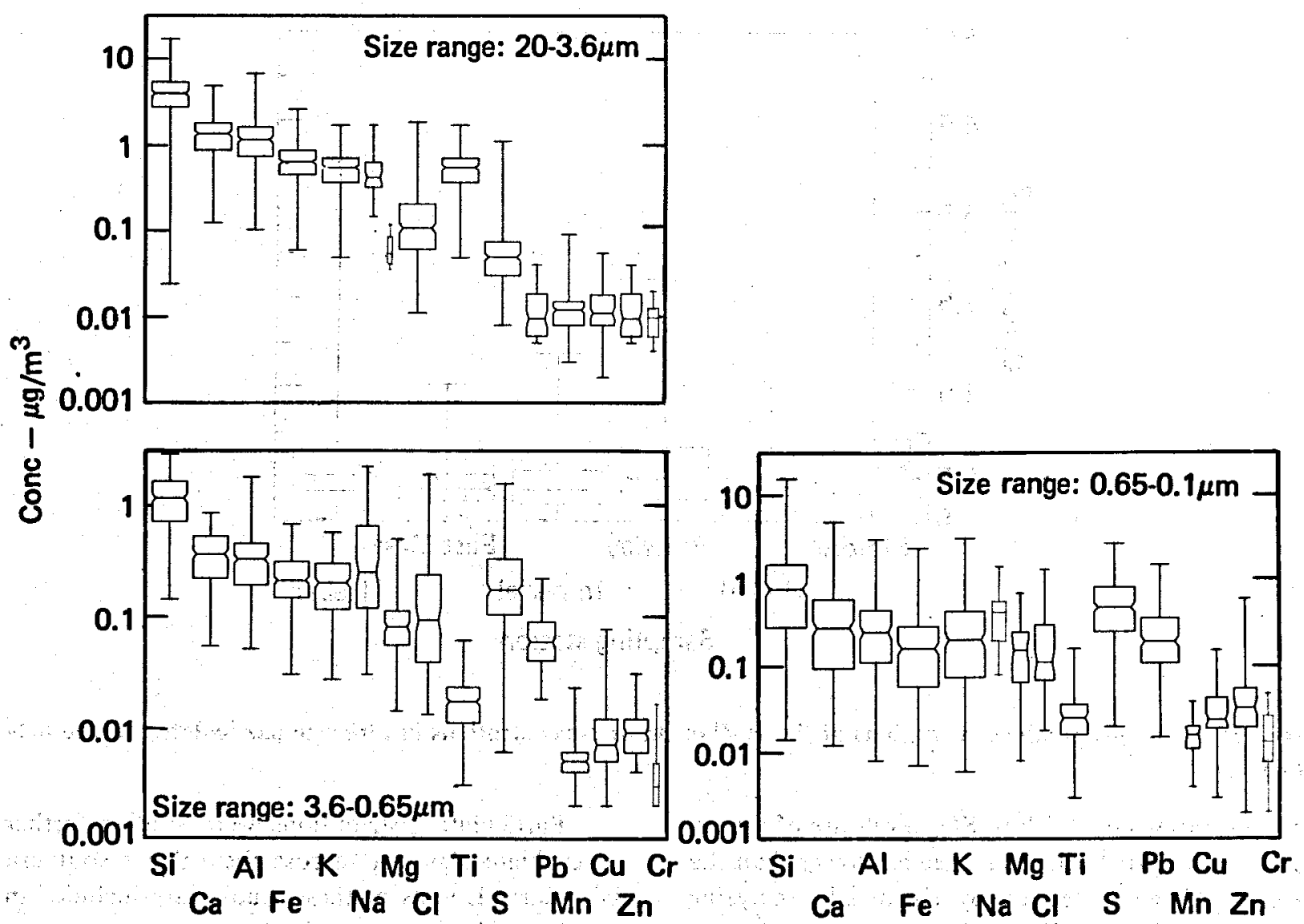

FIG. 23. Median mass concentrations of specific elements in particulates collected at the Brawley site. The data are averaged over 24 hour periods.

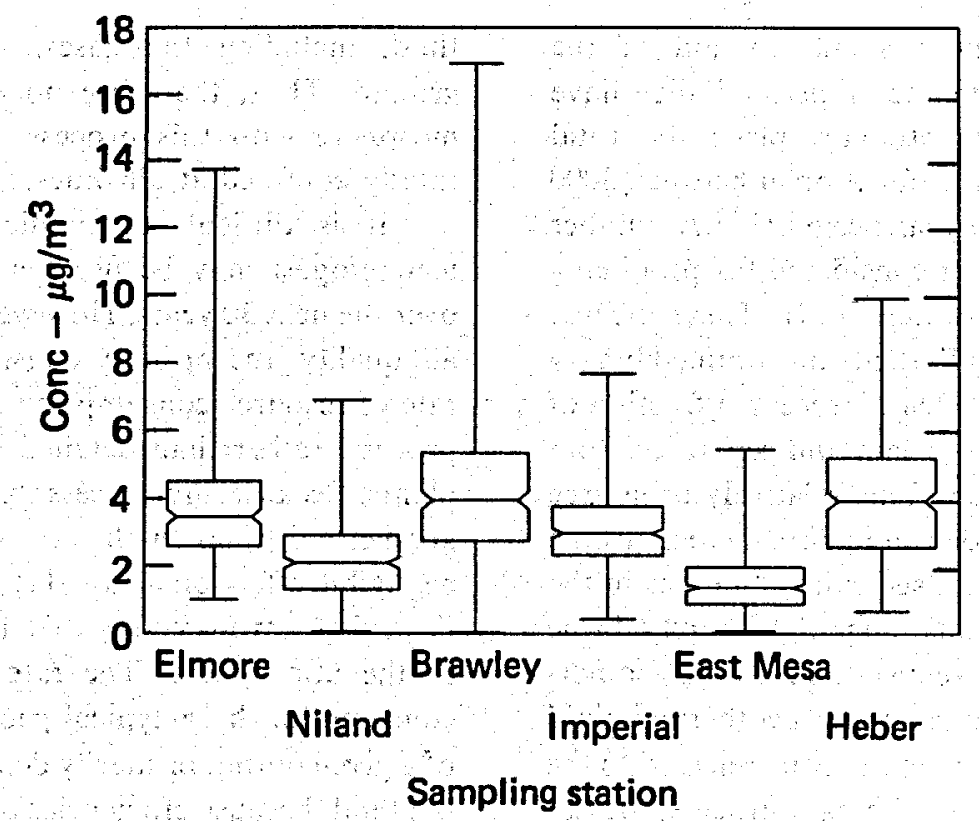

FIG. 24. The geographical variations of the median silicon concentrations in airborme particulates of size 3.6$20 \mu \mathrm{m}$. 


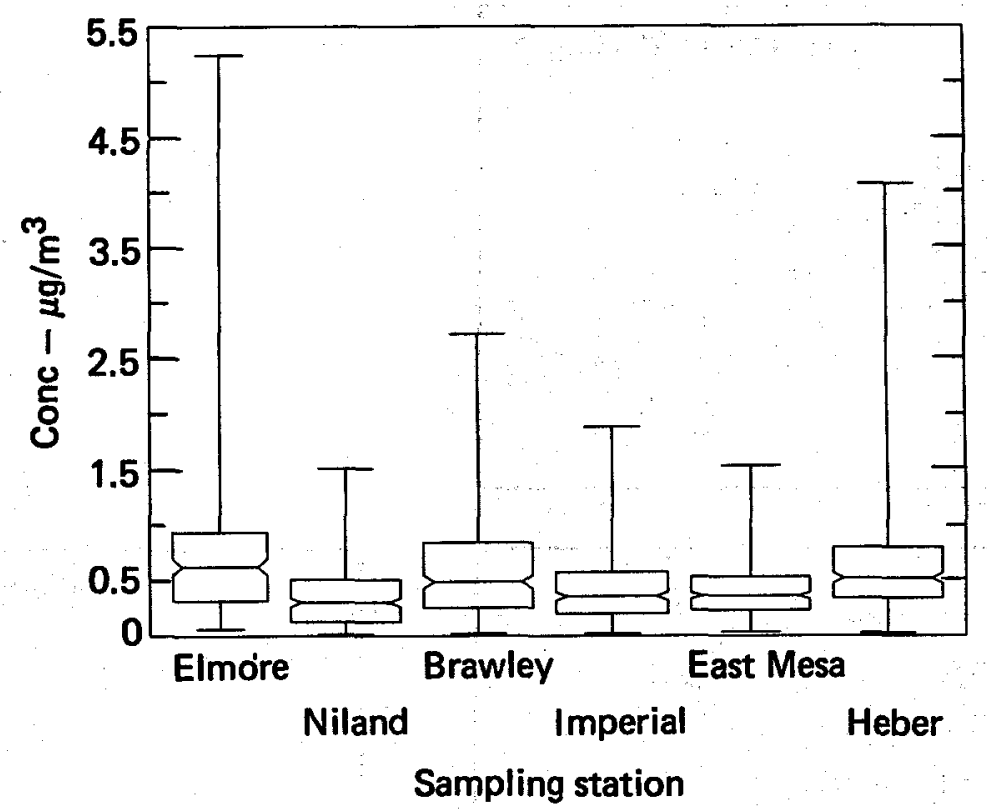

FIG. 25. The geographical variations of the median sulfur concentrations in airborne particulates of size 0.1$0.65 \mu \mathrm{m}$.

concentrations by 3 . Thus, $\mathrm{SO}_{4}$ levels are of the order of $1-4 \mu \mathrm{g} / \mathrm{m}^{3}$. This is somewhat lower than the $4-8 \mu \mathrm{g} / \mathrm{m}^{3}$ levels derived by chemically analyzing the Hi-vol filters collected at all six measurement sites.
Particulate distributions were studied further to evaluate transport across the valley's southern boundary. Details of these studies are included in the Appendix.

\section{GEOTHERMAL SOURCE CHARACTERIZATION}

Even though only a small fraction of the geothermal resources in the Imperial Valley have been explored, recent estimates place the total potential electric power production at between 3000 and $5000 \mathrm{MW}$ for a 30-year period. ${ }^{13,14} \mathrm{~A}$ number of technologies are being considered for producing power from these hot-water fluids. These include flashed steam as well as flashed and confined binary systems. In any flashed-steam process, a fraction of the brine is flashed into steam and separated from the remaining hot water. This relatively brine-free steam fraction may be delivered directly to a turbine or may be used to heat a secondary fluid, as in the binary system. The remaining high-salinity brine may be disposed of by reinjection into the geothermal reservoir. The gases in the geothermal fluid follow the steam fraction and may be released to the atmosphere. In the confined binary process, the hot water, under high pressure, is brought to the surface. After the heat has been extracted all of the fluid, including the gases, is injected into the ground. Thus, there are no emissions to the atmosphere with this process, because the fluid is totally confined at all times.

It is difficult to predict which geothermal technologies may be used in the Imperial Valley over the next 30 years. However, as we are assessing air quality, the primary considerations will be the rate of resource consumption and the nature of the process, rather than detailed designs of the power plants. Because any process that totally confines the geothermal fluid with no release of gases has negligible effect on air quality, we will only address flashed-steam processes that include venting gases to the atmosphere. The rate of geothermal fluid consumption by a typical geothermal power plant of a given output primarily depends on the nature of the fluid, because efficiencies of most conversion cycles range from $10-15 \%$. On the basis of the physical and chemical characteristics of Imperial Valley 
brines and the current designs of proposed flashedsteam power plants, ${ }^{15-17}$ approximately $50 \mathrm{~kg}$ of brine from the Salton Sea and Brawley KGRAs are required per kilowatt-hour of power generated while twice as much fluid is needed to produce the same output from the Heber and East Mesa KGRAs. The difference is due to the higher temperatures observed in the Salton Sea and Brawley fluids.

To estimate the potential emission rate of specific gases from future flashed-steam power plants, it was necessary to characterize the concentrations of these gases in the geothermal fluids. The gases of principal interest are: $\mathrm{H}_{2} \mathrm{~S}, \mathrm{NH}_{3}, \mathrm{CO}_{2}, \mathrm{CH}_{4}$, $\mathrm{Hg}$, and $\mathrm{Rn}$. Sampling and analyzing geothermal fluids are difficult because of their high temperatures and pressures and the multiplicity of complex chemical reactions that may occur within the sampling train. We sampled by allowing the hot water to flash into steam. The steam fraction, which contains the gases, may then be separated and condensed, permitting investigators from the Battelle Pacific Northwest Laboratories (PNL) and LLL to sample the condensate and the gases.

The $\mathrm{H}_{2} \mathrm{~S}$ concentrations were determined by passing the gases through an electrochemical cell. Carbon dioxide and methane concentrations were analyzed by either gas chromatography or mass spectrometry. Elemental mercury concentrations were determined by selective absorption on goldcoated glass beads, followed by volatilization and flameless atomic absorption analysis. Ammonia in the condensate was measured with a specific-ion electrode. For radon analyses, the gas stream was filtered to remove the radon daughter activity, and gas samples were collected in Lucas tubes. The resulting light scintillations, detected by a photomultiplier tube, were used to determine the radon concentrations in the gas stream.

For proprietary reasons, we were allowed to sample only geothermal wells within the Salton Sea and East Mesa KGRAs. A summary of the PNL ${ }^{18}$ and LLL measurements of gas concentrations in the steam fraction of brines obtained from several wells within these KGRAs is shown in Table 3. The data reveal that the concentrations of a specific gas may easily vary over an order of magnitude. This is typical of geothermal fluids from different wells in the same KGRA. By using the data on the rate of fluid consumption and assuming no abatement, we can estimate the potential gas emissions from a particular power plant that uses the flashed-steam process. These emission estimates also are shown in Table 3. Generally, $\mathrm{H}_{2} \mathrm{~S}$ presents the most objectionable impact because of its potential release rate and noxious odor.

TABLE 3. A summary of the gas concentrations in the steam phase of geothermal fluids and estimates of the potential emission per unit power output.

\begin{tabular}{|c|c|c|c|c|c|c|c|}
\hline & \multicolumn{3}{|c|}{ Salton Sea KGRA } & & \multicolumn{3}{|c|}{ East Mesa KGRA } \\
\hline & \multicolumn{2}{|c|}{ Concentrations ( $\mathrm{mg} / \mathrm{kg}$ of fluid) } & \multirow{2}{*}{$\frac{\text { Emissions }}{\mathrm{mg} / \mathrm{kWh}}$} & & \multicolumn{2}{|c|}{ Concentrations ( $\mathrm{mg} / \mathrm{kg}$ of fluid) } & \multirow{2}{*}{$\frac{\text { Emissions }}{\mathrm{mg} / \mathrm{kWh}}$} \\
\hline & Range & Mean & & & Range & Mean & \\
\hline $\mathrm{H}_{2} \mathrm{~S}$ & 1.66 .0 & 3.2 & 160 & $\mathrm{H}_{2} \mathrm{~S}$ & $0.12-1.6$ & 0.54 & 55 \\
\hline $\mathrm{NH}_{3}$ & $20-41$ & 35 & 1750 & $\mathrm{NH}_{3}$ & $1.3-8.1$ & 4.5 & 455 \\
\hline $\mathrm{CO}_{2}$ & $110-3800$ & 1700 & $8.5 \times 10^{4}$ & $\mathrm{CO}_{2}$ & $270-2300$ & 1100 & $1.1 \times 10^{5}$ \\
\hline $\mathrm{CH}_{4}$ & $3.0-10$ & 6.0 & 300 & $\mathrm{CH}_{4}$ & $4.0-56$ & 33 & $3.3 \times 10^{3}$ \\
\hline $\mathrm{Hg}$ & $0.0016-0.002$ & 0.0018 & 0.090 & $\mathrm{Hg}$ & $0.005-0.007$ & 0.006 & 0.6 \\
\hline $\mathbf{R n}$ & $540-1080^{a}$ & $810^{2}$ & $4.1 \times 10^{4 b}$ & $\mathbf{R n}$ & $420-540^{2}$ & $480^{a}$ & $4.9 \times 10^{4 b}$ \\
\hline
\end{tabular}

a pCi/kg of fluid.

b $\mathrm{pCi} / \mathrm{kWh}$. 


\section{AIR QUALITY IMPACT PREDICTIONS}

This section summarizes our assessment of the potential effect on air quality of developing the valley's geothermal resources for electrical power production. This development is expected to be gradual. Several small-scale (10-50 MW) demonstration plants are scheduled to come on-line during the next few years. If these are successful, it is anticipated that the resource will be used principally by multiple $100-\mathrm{MW}$ units to achieve a fullscale production level of several thousand megawatts over the next 20 to 30 years. Thus, this assessment is focused on two separate stages of development: (1) continuous operation of a single 100-MW power plant and (2) a large-scale development consisting of thirty 100-MW units situated within the four KGRAs for a total production level of $3000 \mathrm{MW}$. For detailed descriptions of this assessment the reader is referred to Ref. 2 .

To predict the valley-wide air quality impact of future power generation, it is necessary to resort to atmospheric transport modeling techniques. Two separate computer codes were used for this work. For the single power plant analysis, a steady state Gaussian plume (MSDM) $\operatorname{code}^{19}$ was used and the 3000-MW development scenario was assessed with a three-dimensional particle-in-cell (ATMAS) $\operatorname{code}^{20}$ and augmented by the MSDM code. Both codes use the source emissions data, given in Table 3, and the meteorological data generated by the six air quality stations as input for the impact estimate. The MSDM code computes steady state average concentrations from continuous sources over periods of months to years. It uses joint frequency distributions to describe the probability of meteorological conditions. Similarly, the ATMAS code was designed to assess the long-term impact on regional air quality of continuous emissions from multiple area sources. The particle-in-cell concept. uses a large number of marker particles $(10,000$ $20,000)$ to represent the mass distribution of the emitted species within a three-dimensional Eulerian grid. These marker particles are transported through the grid by pseudo-velocities derived from the component advection and diffusion velocity vectors computed at each cell corner. The advection velocities throughout the grid are obtained by interpolating the winds measured at the six sites, while the diffusion velocities are based on the Gaussian formulation. In a typical time cycle, the particles are transported for one time step according to these pseudo-velocities. This permits a new set of particle coordinates to be computed and results in a new concentration distribution. In source regions, marker particles are continually injected into the grid at a rate consistent with the source strength. The principal advantage of the ATMAS code is its capability to include the important effects of time and spatially varying wind velocities and wind shear. It is a simplified and computationally faster version of the ADPIC transport code. ${ }^{21}$ The ADPIC code has been tested against closed solutions of the advection-diffusion equation and against numerous tracer experiments, out to a distance of about $100 \mathrm{~km}$. Since ATMAS is based on the same model equations as ADPIC and has also been validated against closed solutions of the advection-diffusion equation, we feel that ATMAS has been adequately verified.

The impact analysis of a single power plant is based on an unabated 100-MW flashed-steam unit that may be situated within any one of the four KGRAs. The rate of emissions of $\mathrm{H}_{2} \mathrm{~S}, \mathrm{NH}_{3}, \mathrm{CO}_{2}$, $\mathrm{CH}_{4}, \mathrm{Hg}$, and $\mathrm{Rn}$ were taken from the data of Table 3; we assumed that the rates pertinent to the Brawley and Heber KGRAs are identical to those estimated for the Salton Sea and East Mesa KGRAs, respectively. We assumed emissions at a height of $30 \mathrm{~m}$ to simulate typical cooling tower sources. The meteorological data were obtained from the air quality monitoring stations in the specific KGRA under consideration. Analysis of the results reveals that the ambient air concentrations of $\mathrm{NH}_{3}, \mathrm{Hg}$, and $\mathrm{Rn}$ are several orders of magnitude below the appropriate federal standards. However, this is not true in the case of $\mathrm{H}_{2} \mathrm{~S}$. Figure 26 gives the probability of exceeding the California one-hour standard ( $30 \mathrm{ppb}$ ) as a function of radial distance from the power plant. A review of the figure indicates that, in the absence of abatement, the standard is exceeded out to a distance of $5 \mathrm{~km}$ in the Salton Sea and Brawley KGRAs and to about $\mathbf{2 ~ k m}$ in the Heber and East Mesa resource areas.

Analysis of the $3000-\mathrm{MW}$ development scenario (thirty 100-MW power plants) is based on the siting pattern shown in Fig. 27. The distribution is $1400,600,700$, and $300 \mathrm{MW}$ within the Salton Sea, Brawley, Heber, and East Mesa KGRAs, 


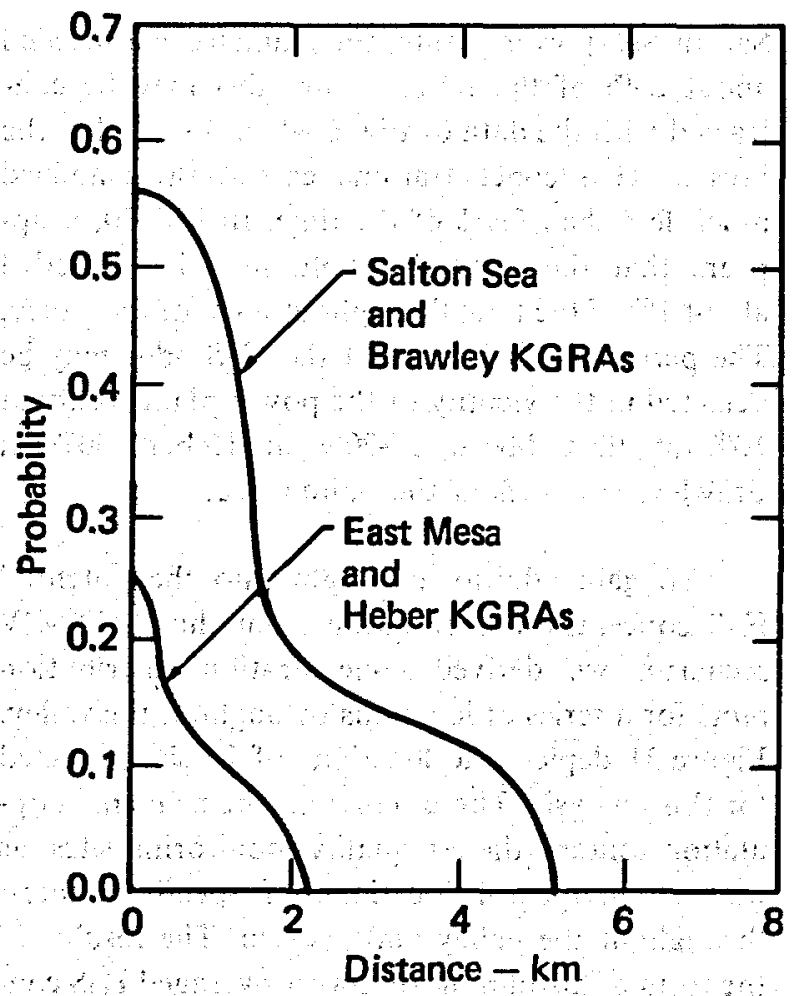

FIG. 26. The calculated probability of exceeding the $30 \mathrm{ppb}$, one hour California air quality standard for $\mathrm{H}_{2} \mathrm{~S}$, as a function of radial distance from a 100 MW nashed steam power plant situated within any one of the four KGRAs. The $\mathrm{H}_{2} \mathrm{~S}$ emission rate is assumed to be $160 \mathrm{mg} / \mathrm{kWh}$ for the Salton Sea and Brawley KGRAs, and $55 \mathrm{mg} / \mathrm{kWh}$ for the East Mesa and Heber KGRAs.

respectively. ${ }^{22}$ This distribution is based on estimated resource potentials Again, it is assumed that all of the power plants use the flashed-steam process and that all gases liberated in the flashing process are vented into the atmosphere to allow direct use of the data of Table 3. The emissions from each power unit within a KGRA were assumed to combine into a quasi-area source uniform in the horizontal direction, Gaussian in the vertical direction, and centered at a height of $30 \mathrm{~m}$. The advection part of the transport equation in the ATMAS code uses the hourly-averaged wind velocities measured at the six sites; the diffusion part is based on the $\sigma_{\theta}$ data from the Heber site. Upper level winds were derived by standard power-law profiles. The air quality impact predictions were made for one year; however, even though the ATMAS code is computationally much faster than the ADPIC version of the code, it still requires considerable computer time. Consequently, the annual assessment is based on a one-month simulation during each season (April, July, October, and January, 1977-78). These and the remaining eight months were analyzed by the fast-running MSDM code for unusual concentration distributions; however, the results were essentially identical to those obtained for the four months mentioned above.

The valley-wide annual averaged $\mathrm{H}_{2} \mathrm{~S}$ concentrations calculated by the ATMAS code for this development scenario are depicted in Fig. 28. These concentrations range up to about $20 \mathrm{ppb}$, with the highest values in the Salton Sea and Brawley KGRAs-where most of the power units are situated. Secondary maxima (of about $2 \mathrm{ppb}$ ) occur within the Heber and East Mesa KGRAs. These values may be compared with the baseline $\mathrm{H}_{2} \mathrm{~S}$ air quality measurements, shown in Fig. 6, which are generally below $5 \mathrm{ppb}$.

Since the principal concern with $\mathrm{H}_{2} \mathrm{~S}$ emissions is the noxious odor, short-term-averaged concentrations are more pertinent than annual averages. Thus, we are not only interested in the probability of the ambient air concentrations exceeding the air quality standard but also the probability of exceeding the odor threshold of $5-10 \mathrm{ppb}^{23}$ for the majority of the population. Consequently, we have calculated the probability with which the one-houraverage $\mathrm{H}_{2} \mathrm{~S}$ concentrations exceed $30 \mathrm{ppb}$ (the

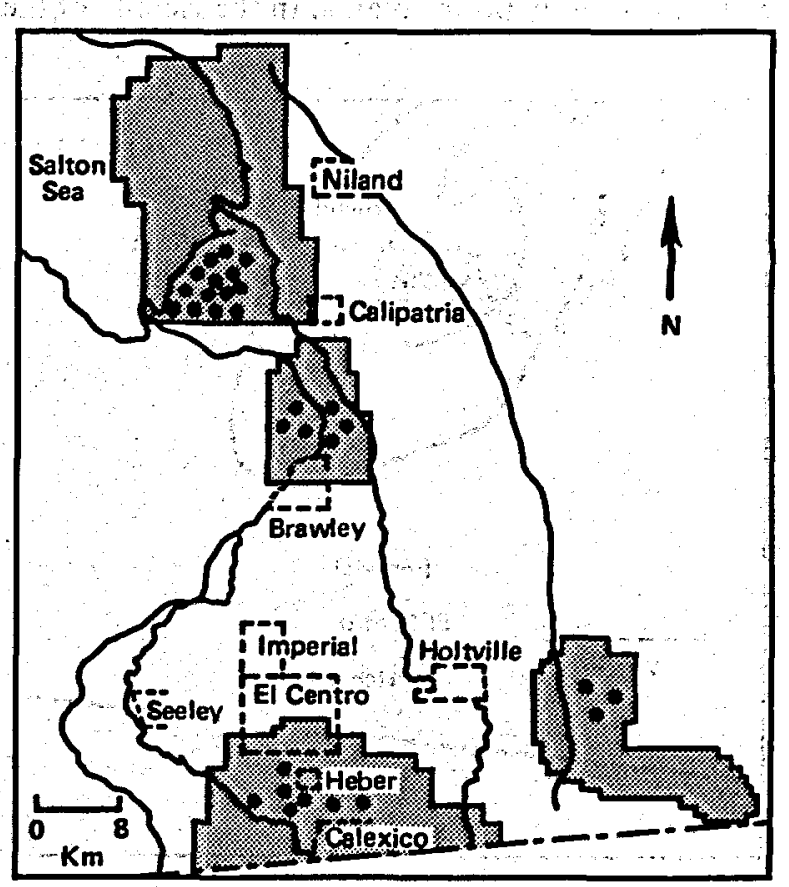

FIG. 27. Siting pattern for the 30 power plants in the $3000-\mathrm{MW}$. development scenario. 


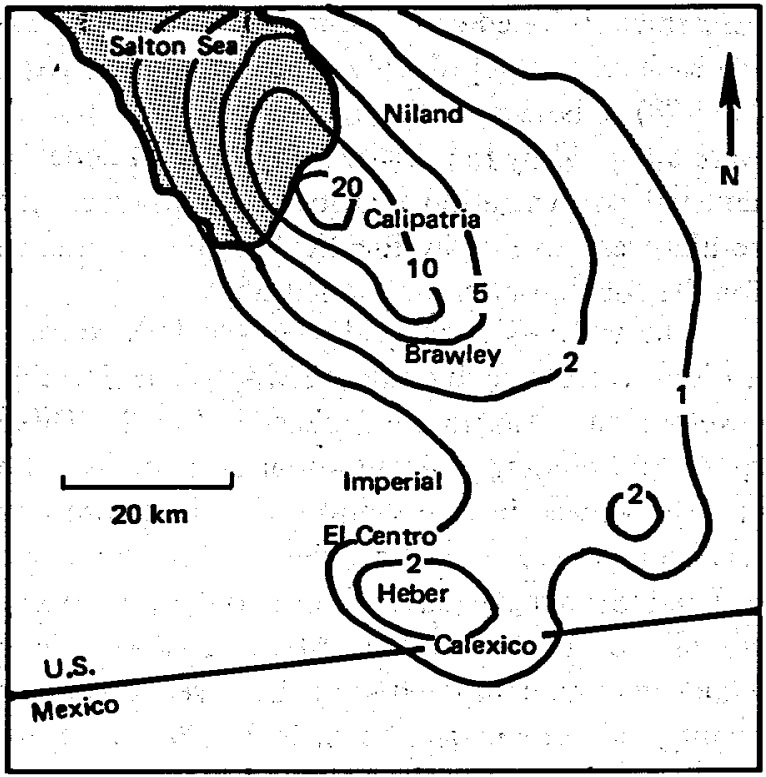

FIG. 28. The estimated annual average of the hourly averaged ground level $\mathrm{H}_{2} \mathrm{~S}$ concentrations (ppb) resulting from the 3000-MW scenario.

standard), as well as the probability of exceeding $7 \mathrm{ppb}$ (the approximate mid-point of the odor detection range). The results are shown in Figs. 29 and 30, respectively. The data of Fig. 29 reveal that the standard is exceeded $1 \%$ of the time over an area of approximately $1500 \mathrm{~km}^{2}$ surrounding the Salton Sea and Brawley power plants. In the vicinity of the

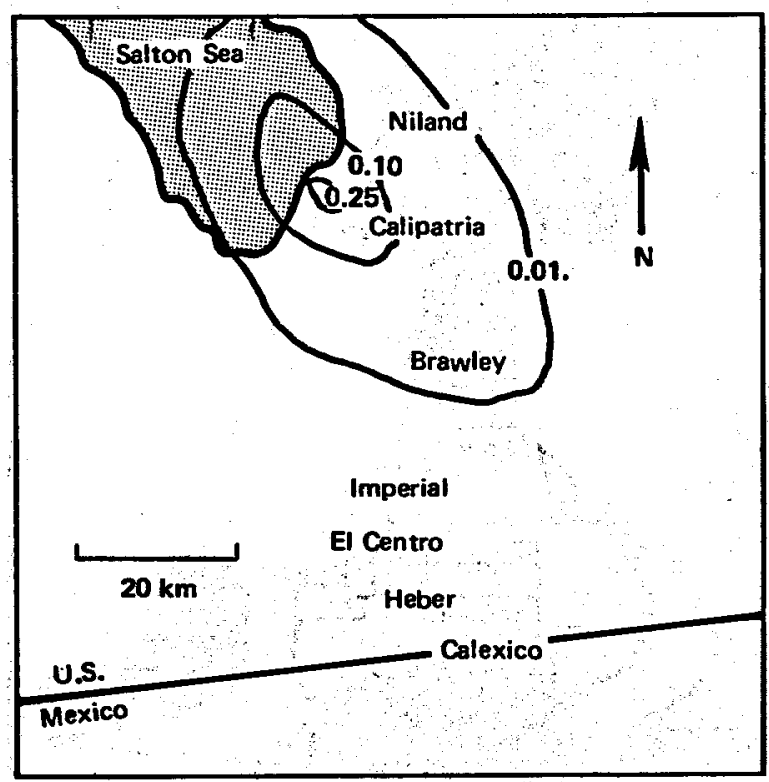

FIG. 29. Fraction of time the hourly averaged $\mathrm{H}_{2} \mathrm{~S}$ ground level concentrations is estimated to exceed $\mathbf{3 0}$ ppb.
Salton Sea power plants, the standard is exceeded about $25 \%$ of the time. Again, this may be contrasted with the data of Fig. 6 which shows that the present $\mathrm{H}_{2} \mathrm{~S}$ concentrations exceed the standard much less than $0.1 \%$ of the time. In Fig. 30, it appears that the odor threshiold may be exceeded about $1 \%$ of the time throughout most of the valley. The percentage of time that the $\mathrm{H}_{2} \mathrm{~S}$ odor may be detected in the vicinity of the power plants is about $10 \%$ at East Mesa, $15-20 \%$ at Heber, $50 \%$ at Brawley, and $75 \%$ at the Salton Sea.

To gain additional insight into the potential $\mathrm{H}_{2} \mathrm{~S}$ concentrations resulting from this $3000-\mathrm{MW}$ scenario, we derived concentration distribution plots for a series of locations throughout the valley. Figure 31 depicts the locations of 22 sites selected for this analysis. These represent the principal population centers, the air quality monitoring sites, as well as peripheral locations of specific interest throughout the valley and Mexico. The results, in the form of histograms of hourly averaged $\mathrm{H}_{2} \mathrm{~S}$ concentrations for each location, are shown in Fig. 32. As expected, the locations exhibiting the greatest probability of exceeding the California air quality standard are situated within the Brawley-Salton Sea area (Locations 13-15). Thus, one notes that the air quality within the northern towns of Niland, Calipatria, Westmorland, and Brawley (Locations

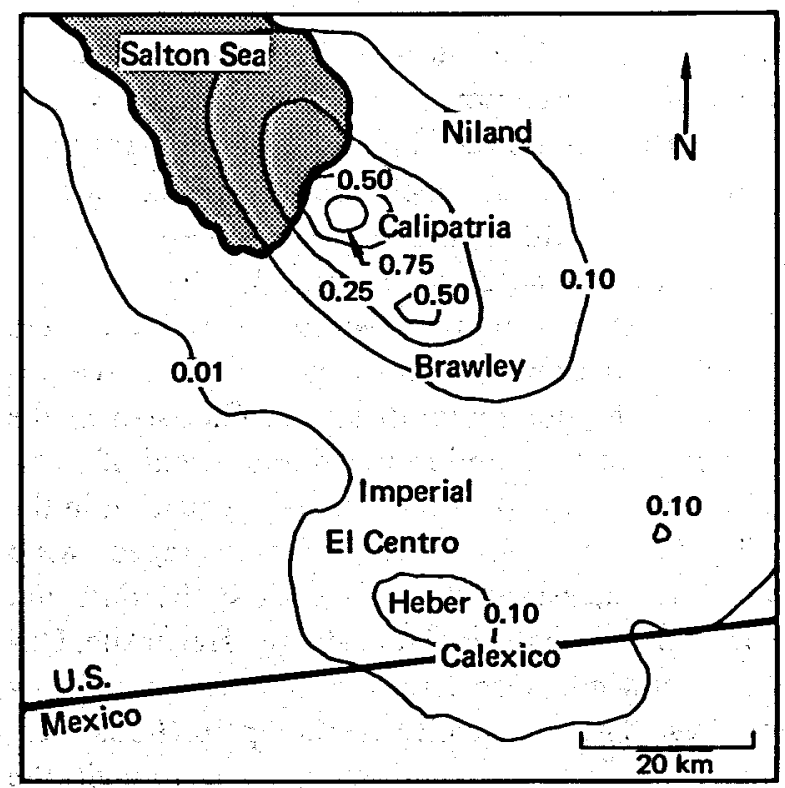

FIG. 30. Fraction of time the hourly averaged $\mathrm{H}_{2} S$. ground level concentrations is estimated to exceed 7 ppb. 


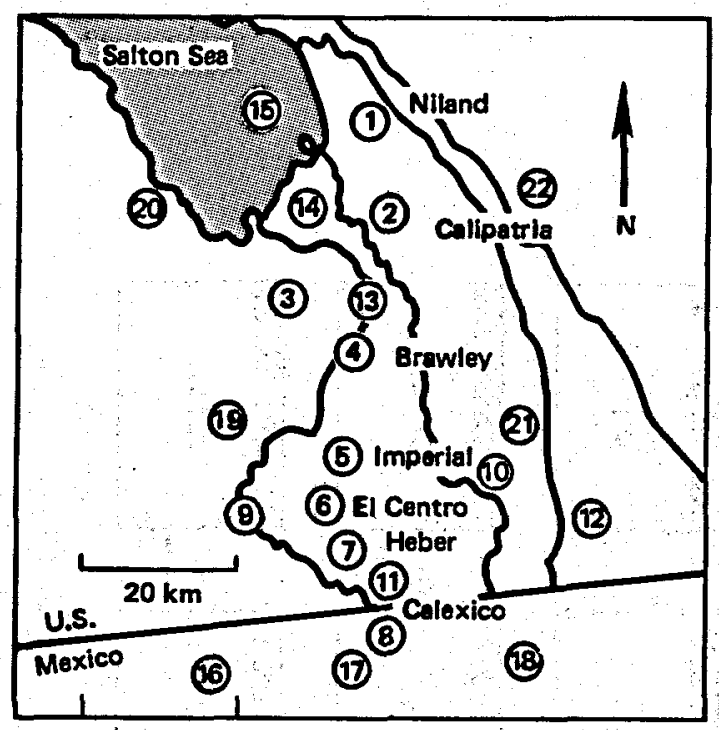

FIG. 31. The locations of the 22 analysis sites.

$1-4$, in that order) exceeds the standard fairly frequently, while the more southern cities of Imperial (5), El Centro (6), Holtville (10), and Calexico (11) are affected minimally. It is also of interest to note that there is only minor impact from this development scenario south of the U.S.-Mexico border. The relationships of these distributions to the California air quality standard are illustrated by the two numbers appearing in the histograms. The top number denotes the number of calendar days per year with at least one hourly averaged $\mathrm{H}_{2} \mathrm{~S}$ concentration exceeding the California standard; the lower number represents the average number of hours per day that such episodes occur. A review of these data indicates that the northern population centers experience episodes of greater than $30 \mathrm{ppb}$ from 77 . 228 days per year for an average of 2 to 3 hours per day; a considerable impact.
Since $\mathrm{H}_{2} \mathrm{~S}$ oxidizes in the atmosphere to $\mathrm{SO}_{2}$, the calculations included a first order chemical transformation with an $\mathrm{H}_{2} \mathrm{~S}$ half-life of 13 hours. Figure 33 shows the annual average $\mathrm{SO}_{2}$ concentrations resulting from this $3000-\mathrm{MW}$ scenario. The maximum concentrations, about $2 \mathrm{ppb}$, which occur over the Salton Sea are insignificant compared with the California one hour average standard of $500 \mathrm{ppb}$ as well as the 24 hour standard of $50 \mathrm{ppb}$. Detailed analysis of the $\mathrm{SO}_{2}$ hourly averaged concentrations indicates that $80 \%$ of the values are less than $2 \mathrm{ppb}$ with only rare excursions exceeding $100 \mathrm{ppb}$.

The impact of $\mathrm{NH}_{3}, \mathrm{Hg}$, and $\mathrm{Rn}$ emissions from this scenario was also computed and found insignificant. The maximum 1 hour $\mathrm{NH}_{3}$ concentration was more than a factor of ten less than the federal standard of $3.5 \mu \mathrm{g} / \mathrm{m}^{3}$, which is approximately the odor threshold. The federal occupational standard for $\mathrm{Hg}$ is $100 \mu \mathrm{g} / \mathrm{m}^{3}$, while the maximum level calculated throughout the valley was more than a factor of 200 below that level. Likewise, the maximum $R n$ concentration resulting from this scenario was more than five orders of magnitude below the federal standard of $1000 \mathrm{pCi} / \mathrm{m}^{3}$.

From the data of Table 3, it is evident that practically all of the mass of the gaseous power plant emissions is due to $\mathrm{CO}_{2}$. However, even in spite of this, the maximum calculated ambient air concentrations for this $3000-\mathrm{MW}$ scenario were always less than $50 \mathrm{ppm}$ and typically less than $10 \mathrm{ppm}$. Thus, the additional contributions of $\mathrm{CO}_{2}$ to ambient levels from the power plants are well within the cormal atmospheric fluctuations given in Fig. 20. 

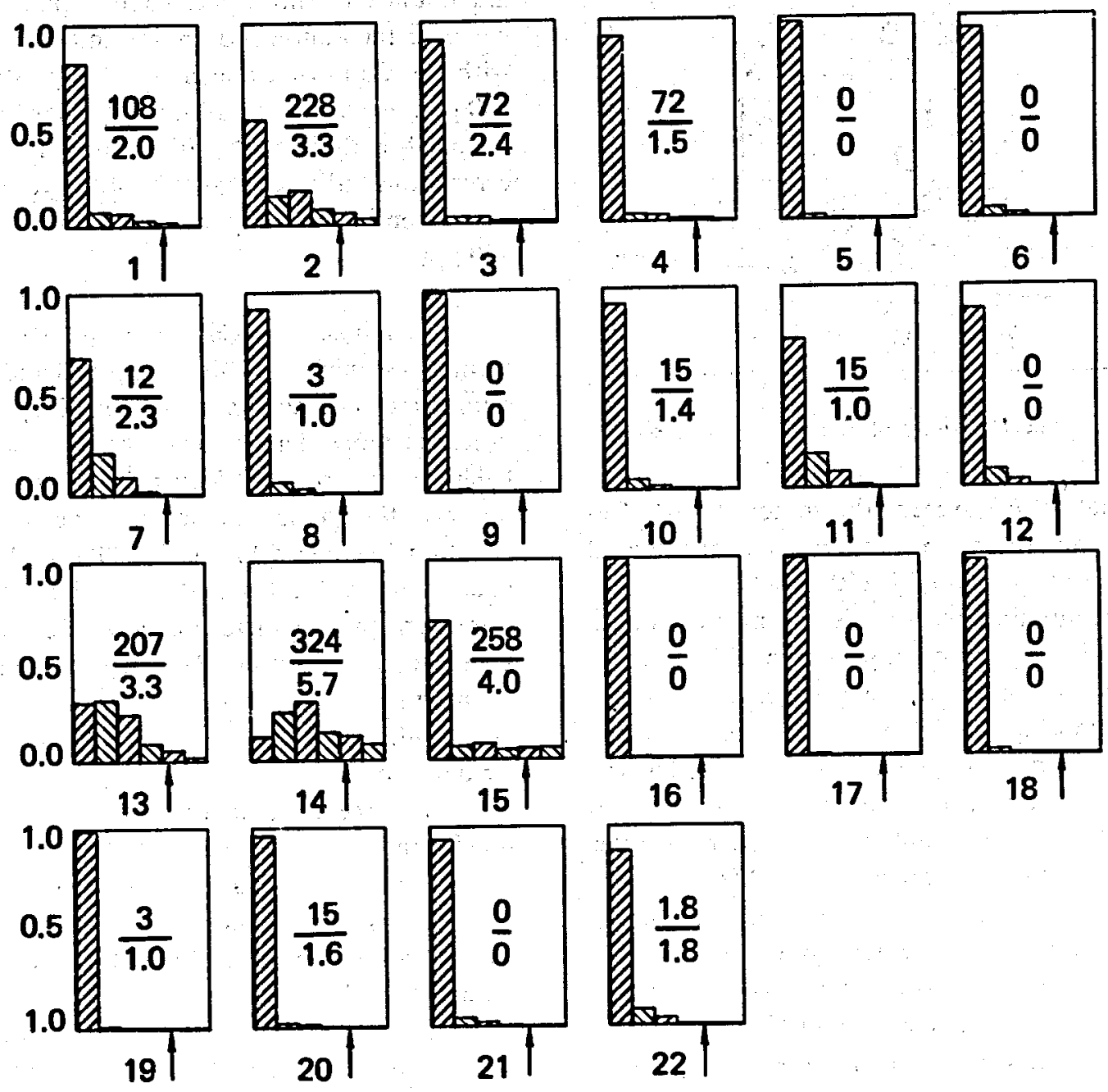

FIG. 32. Histograms of the hourly averaged ground level $\mathrm{H}_{2} \mathrm{~S}$ concentrations for the 22 sites shown in Fig. 31 . The compartments correspond to concentration intervals 0-5, 5-10, 10-20, 20-30, 30-50, and above $50 \mathrm{ppb}$. The arrow on the horizontal axis indicates the location of the $30 \mathrm{ppb}$ one hour California air quality standard for $\mathrm{H}_{2} \mathrm{~S}$. Also shown are the number of days per year with at least one exceed of the $30 \mathrm{ppb}$ level (top number), and the average length in hours of an episode (bottom number). 


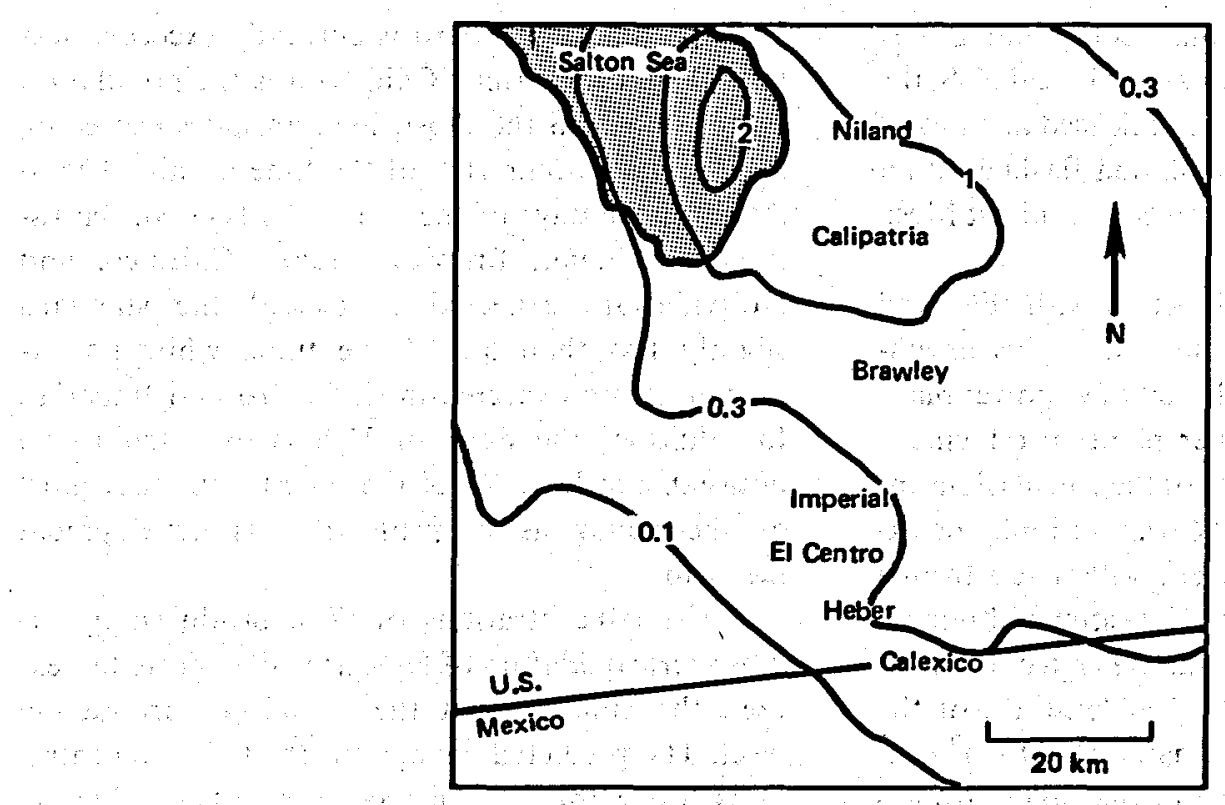

FIG. 33. The estimated annual average of the hourly averaged ground level $\mathrm{SO}_{2}$ concentrations (ppb) resulting from the $3000 \mathrm{MW}$ scenario.

\section{SUMMARY}

This report presents a regional assessment of the potential impact on air quality that may result from developing the Imperial Valley's geothermal resources for power production. This assessment is based on measurements of baseline air quality and meteorology, analyses of geothermal fluids for power plant emission estimates, and atmospheric transport modeling of pollutant emissions. Nearly all geothermal power generation schemes will release a variety of gaseous substances to the atmosphere. Of primary environmental significance is the release of $\mathrm{H}_{2} \mathrm{~S}$ because of its noxious odor and potential release rates.

The air quality measurements include the concentrations of $\mathrm{H}_{2} \mathrm{~S}, \mathrm{SO}_{2}, \mathrm{O}_{3}, \mathrm{NO}, \mathrm{NO}_{\mathrm{x}}, \mathrm{CO}_{2}, \mathrm{Rn}$, $\mathrm{Hg}$, and particulates at six sites in the valley. The hourly averaged $\mathrm{H}_{2} \mathrm{~S}$ and $\mathrm{SO}_{2}$ concentrations were generally less than $10 \mathrm{ppb}$ with a few excursions above this value. Rarely, however, did the concentrations exceed the California air quality standard of $30 \mathrm{ppb}$. Most NO and $\mathrm{NO}_{\mathrm{x}}$ concentrations were less than $20 \mathrm{ppb}$. The daily median $\mathrm{O}_{3}$ concentrations measured at the six locations ranged from 15 . $35 \mathrm{ppb}$. However $5 \%$ of the hourly averaged daily maximum values exceeded $100 \mathrm{ppb}$, the California air quality standard. Due to intensive agricultural activities throughout the valley the $\mathrm{CO}_{2}$ concentrations varied widely; from about $260 \mathrm{ppm}$ to over $450 \mathrm{ppm}$. The daily median values typically ranged between $320-340 \mathrm{ppm}$. The principal air pollutant within the valley are particulates. The mass of total suspended particulates often exceeds the California air quality standard of $100 \mu \mathrm{g} / \mathrm{m}^{3}$. Monthly median values ranged from about $60-250 \mu \mathrm{g} / \mathrm{m}^{3}$. Elemental analyses of these particulates indicates that most of the mass is $\mathrm{Si}, \mathrm{Ca}, \mathrm{Al}, \mathrm{Fe}$ and $\mathrm{K}$. Lesser quantities of $\mathrm{S}, \mathrm{Pb}$, and $\mathrm{Br}$ are also present. The median $\mathrm{Hg}$ and $\mathrm{Rn}$ concentrations were $3 \mathrm{ng} / \mathrm{m}^{3}$ and $280 \mathrm{pCi} / \mathrm{m}^{3}$, respectively.

The meteorological parameters of interest for this assessment were wind velocity and atmospheric stability. These measurements reveal a predominantly strong southwesterly to northwesterly flow across the valley during the winter and a southeasterly flow component that is added during the summer. Atmospheric stability estimates revealed that stability category $\mathrm{F}$ occurs most frequently during the winter while the slightly less stable E category predominates during the summer.

Chemical analyses of the geothermal fluids in the Salton Sea and East Mesa KGRAs gave estimates of the potential emission rates of $\mathrm{H}_{2} \mathrm{~S}, \mathrm{NH}_{3}$, 
$\mathrm{CO}_{2}, \mathrm{CH}_{4}, \mathrm{Hg}$, and $\mathrm{Rn}$ from geothermal power generation. Results of these analyses reveal $\mathrm{H}_{2} \mathrm{~S}$, the primary gas of concern, may be released at rates of 160 and $55 \mathrm{mg} / \mathrm{kWh}$ from unabated flashed steam power plants utilizing the Salton Sea and East Mesa fluids, respectively.

Using these data in conjunction with advanced air quality modeling techniques, an impact assessment was made for (a) a single $100 \mathrm{MW}$ power plant and (b) thirty $100 \mathrm{MW}$ power plants producing a total of $3000 \mathrm{MW}$. The results of the calculations indicate that the $\mathrm{H}_{2} \mathrm{~S}$ air quality standard may be exceeded out to distances of several kilometers from a single unabated power plant. The estimated impact of the $3000 \mathrm{MW}$ scenario is that the $\mathrm{H}_{2} \mathrm{~S}$ concentrations may exceed the standard at least $1 \%$ of the time over an area of approximately $1500 \mathrm{~km}^{2}$ centered within the northern part of the valley. An additional $5-10 \mathrm{~km}^{2}$ within the Heber and East Mesa areas are similarly impacted. This may be contrasted with the baseline data indicating that the
$\mathrm{H}_{2} \mathrm{~S}$ air quality standard is currently exceeded less than $0.1 \%$ of the time. Calipatria is the population center impacted the most; here episodes exceeding the standard occur $10 \%$ of the time on about twothirds of the days of the year. The $\mathrm{H}_{2} \mathrm{~S}$ concentrations in Niland, Brawley, Heber, Calexico, and Holtville are expected to exceed the standard slightly less than $5 \%$ of the time, while no exceedances are expected in El Centro and Imperial. In addition, the odor of $\mathrm{H}_{2} \mathrm{~S}$ is expected to be noticeable at least $1 \%$ of the time throughout most of the valley as a result of this development scenario.

The concentrations of $\mathrm{SO}_{2}$, produced by atmospheric oxidation of $\mathrm{H}_{2} \mathrm{~S}$, are not expected to exceed the standards at the $3000 \mathrm{MW}$ production level. The predicted changes in the $\mathrm{CO}_{2}$ concentrations are within the normal atmospheric fluctuations. The emissions of $\mathrm{NH}_{3}, \mathrm{Hg}$, and $\mathrm{Rn}$ are anticipated to produce concentrations several orders of magnitude below appropriate standards.

\section{ACKNOWLEDGMENTS}

The authors appreciate the valuable support provided by Gale Holladay, Don Mullenhoff, Robert Steinhaus, Don Garka, and Doug Sawyer, all of LLL, for the design, construction, installation, and operation of the air quality monitoring systems. This includes the assistance provided by Claude Finnell and John Taylor of the Imperial County Air Pollution Control District. Valuable quality assurance efforts were provided by Edward Jeung of the Air and Industrial Hygiene Laboratory and Mark Cher of Rockwell International. We should also like to thank John Hill and Charles Morris of LLL as well as Dave Robertson from BattellePacific Northwest Laboratories for their gas analyses of the geothermal brines. Considerable efforts were also expended by Robert Flocchini and Tom Cahill of the University of California at Davis for the elemental analyses of the particulate samples. Valuable contributions were made by Vance Fowler and Liene Boone, of LLL, in the areas of data processing and atmospheric transport calculations. The authors also thank William Quam of EG\&G (Goleta) for his support of the aerial sampling of airborne particulates. Finally, the authors also appreciate the helpful comments and valuable guidance provided by Paul Phelps and Lynn Anspaugh during the entire conduct of the program.

$\mathrm{BS} / \mathrm{skg}$ 


\section{REFERENCES}

1. P. H. Gudiksen, K. C. Lamson, M. C. Axelrod, V. Fowler, and R. A. Nyholm, Imperial Valley Environmental Project: Baseline Air Quality and Meteorological Data, Lawrence Livermore Laboratory, Livermore, CA, UCID-18212 (1979).

2. D. L. Ermak, R. A. Nyholm, and P. H. Gudiksen, Imperial Valley Environmental Project: Air Quality Assessment, Lawrence Livermore Laboratory, Livermore, CA, UCRL-52699 (1979).

3. R. S. Braman and D. L. Johnson, "Selective Absorption Tubes and Emission Technique for Determination of Ambient Forms of Mercury in Air," Environmental Science and Technology 8, 996-1003 (1974).

4. W. Jacobi, "A Double-Filter Device to Measure Radon and Thoron in the Breath," in Proc. Symposium on the Assessment of Radioactive Body Burdens in Man, Heidelberg, May 1964,(IAEA, Vienna, 1964), p. 275-289.

5. National Oceanic and Atmospheric Administration, Star Program Data, Environmental Data Science, Asheville, NC.

6. L. A. Ripperton, L. Kornreich, and J. B. Worth, Journal of the Air Pollution Control Association 20, 589. 592 (1970).

7. P. F. Lester and R. L. Simon, Fluxes of Air Pollutants into the California Desert from the Los Angeles Basin, final report submitted to The Bureau of Land Management by Global Weather Consultants, Inc., San Jose, California (1978).

8. R. Chatfield and H. Harrison, "Ozone in the Remote Troposphere: Mixing Versus Photochemistry," Journal of Geophysical Research 81, 421-424 (1976).

9. California Air Quality Data, California Air Resources Board Report 8(1), (1976).

10. D. Davis, $\mathrm{OH}$ Radical Measurements: Impact on Power Plant Plume Chemistry, final report to Electric Power Research Institute, Report No. EA-465, Research Project 676, Georgia Institute of Technology, Atlanta, Georgia (1977).

11. W. L. Chameides and J. C. G. Walker, “A Time-Dependent Photochemical Model for Ozone Near the Ground," Journal of Geophysical Research 81, 413-420 (1976).

12. S. B. Verma and N. J. Rosenberg, "Carbon Dioxide Concentration and Flux in a Large Agricultural Region of the Great Plains of North America," Journal of Geophysical Research 81, 399-405 (1976).

13. J. L. Renner, D. E. White, and D. L. Williams, Hydrothermal Convection Systems in Assessments of Geothermal Resources of the United States, U.S. Geological Survey Circ. 726 (1975).

14. D. Towse, An Estimate of the Geothermal Energy Resource in the Salton Trough, Lawrence Livermore Laboratory, Livermore, CA, UCRL-51851.

15. M. Walker, Republic Geothermal, Santa Fe Springs, CA, private communications (1978).

16. W. Smith, Union Oil Co., Santa Rosa, CA, private communication (1978).

17. M. Carroll, San Diego Gas and Electric Co., San Diego, CA, private communication (1978).

18. D. E. Robertson, J. S. Fruchter, J. D. Ludwick, C. L. Wilkerson, E. A. Crecelius, and J. C. Evans, "Chemical Characterization of Gases and Volatile Heavy Metals in Geothermal Effluents, Geothermal Energy: A Novelty Becomes a Resource," Geothermal Resources Council, Transactions 2, 579-582 (197.8).

19. D. L. Ermak and R. A. Nyholm, Multiple Source Dispersion Model, Lawrence Livermore Laboratory, Livermore, CA, UCRL-52592 (1978).

20. D. L. Ermak, R. A. Nyholm, and R. Lange, ATMAS: A Three-Dimensional Atmospheric Transport Model to Treat Multiple Area Sources, Lawrence Livermore Laboratory, Livermore, CA, UCRL-52603 (1978).

21. R. Lange, "ADPIC-A Three-Dimensional Particle-in-cell Model for the Dispersal of Atmospheric Pollutants and Its Comparison to Regional Tracer Studies," Applied Meteorology 17, 320-329 (1978).

22. D. L. Ermak, Potential Growth of Electric Power Production from Imperial Valley Geothermal Resources, Lawrence Livermore Laboratory, Livermore, CA, UCRL-52252 (1977).

23. D. F. Adams, F. A. Young and R. A. Huhr, "Evaluation of an Odor Perception Threshold Test Facility," Tappi 51, 62A-67A (1968). 

APPENDIX

\section{SPECIAL STUDIES}

A study was performed during July 1977 to measure the concentrations of particulates in the vicinity of the U.S.-Mexico border because visibility is often markedly degraded in that area by sizeable smoke and dust plumes. Of special interest to geothermal development was the definition of airborne particulate $S$ concentrations in the area. The study was carried out by investigators from U.C. Davis and EG\&G (Santa Barbara). A network of surface samplers situated along the border, as shown in Fig. A-1; was operated by U.C. Davis. In addition, a particulate sampler, mounted onboard an EG\&G aircraft, collected samples at selected altitudes above the surface network. The surface samplers consisted of two-stage dichotomous filter units, while a multistage impactor was used on the aircraft.

The samples, analyzed at U.C. Davis, yielded the concentrations of $S$ and other elements within two particle size groups: a small size fraction containing particles of less than $2 \mu \mathrm{m}$ in diameter, and a large size fraction containing particles greater than $2 \mu \mathrm{m}$ in diameter. The surface concentrations of $\mathrm{S}$ and $\mathrm{Pb}$ in the small size fraction, and $\mathrm{Si}$ in the large size fraction are shown in Fig. A-2 for two periods characterized by either southeasterly or northeasterly winds. The $\mathbf{S}$ concentrations apparently are little influenced by geography or meteorology; however, the $\mathrm{Pb}$ concentrations are higher by factors of 2 to 4 during the period with southeasterly winds, and also peak at the Calexico-Mexicali site (Site 5). This is not really surprising since $\mathrm{Pb}$ originates principally from car exhaust, and the urban plume generated by Mexicali, a city of over one million, is expected to be much larger than that generated by Calexico. Also note in Fig. A-2 that the Si concentrations in the large size fractions are appreciably higher during the period of southeasterly winds. The peaking at Site 3 is not well understood. The elemental concentrations measured by the airborne sampler at selected altitudes-up to 3000 feet-above the surface sampling network are shown in Fig. A-3. These data, derived from samples collected during a period of southeasterly winds, indicate essentially uniform concentrations up to at least 3000 feet. This agrees well with visual observations at the time of sample collections, when visibility was markedly degraded at all sampling altitudes. As expected, the elemental ratios derived from the samples collected at various altitudes were similar to those obtained from the surface network. 


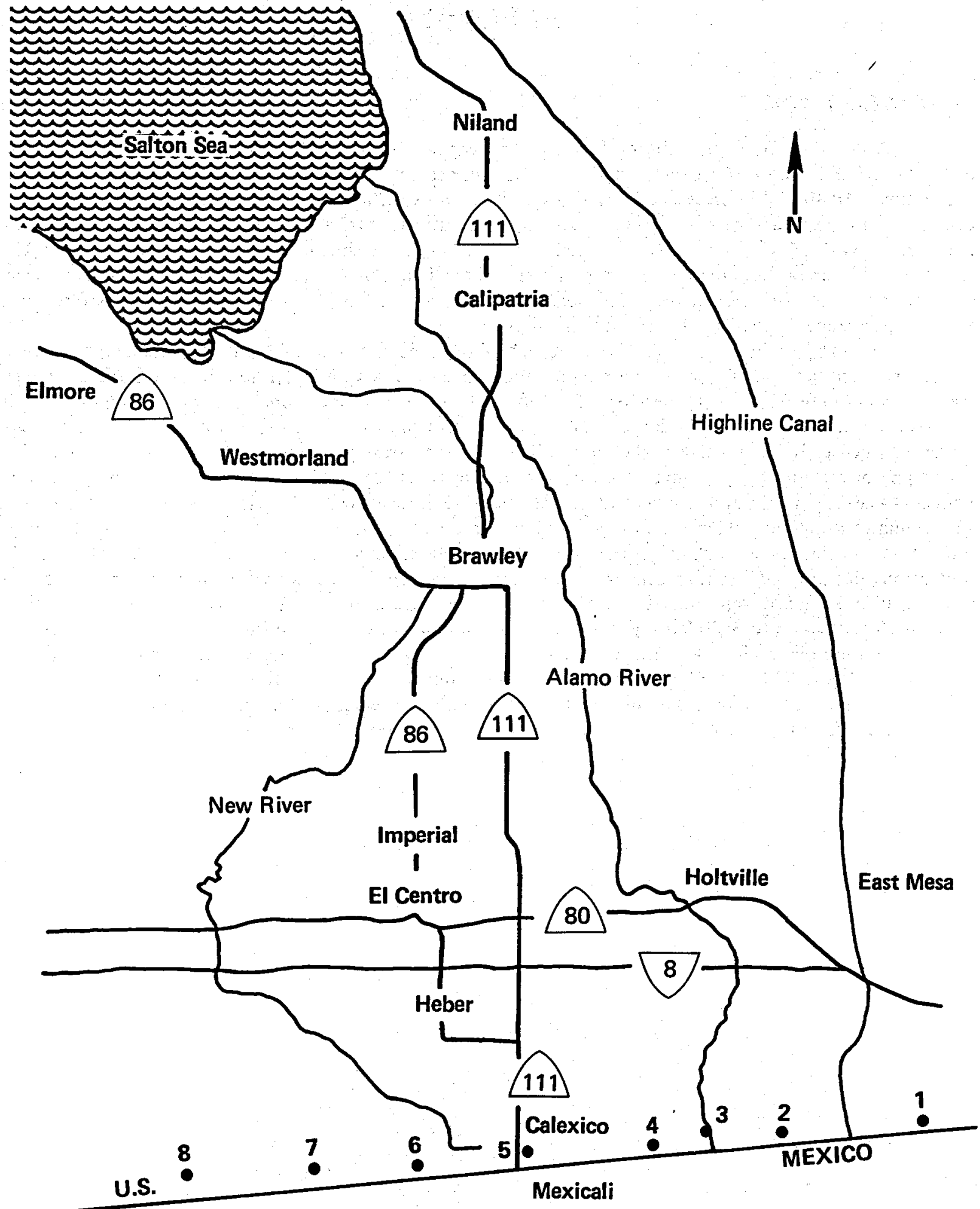

FIG. A-1. Locations of surface sampling sites along U.S.-Mexico border. 

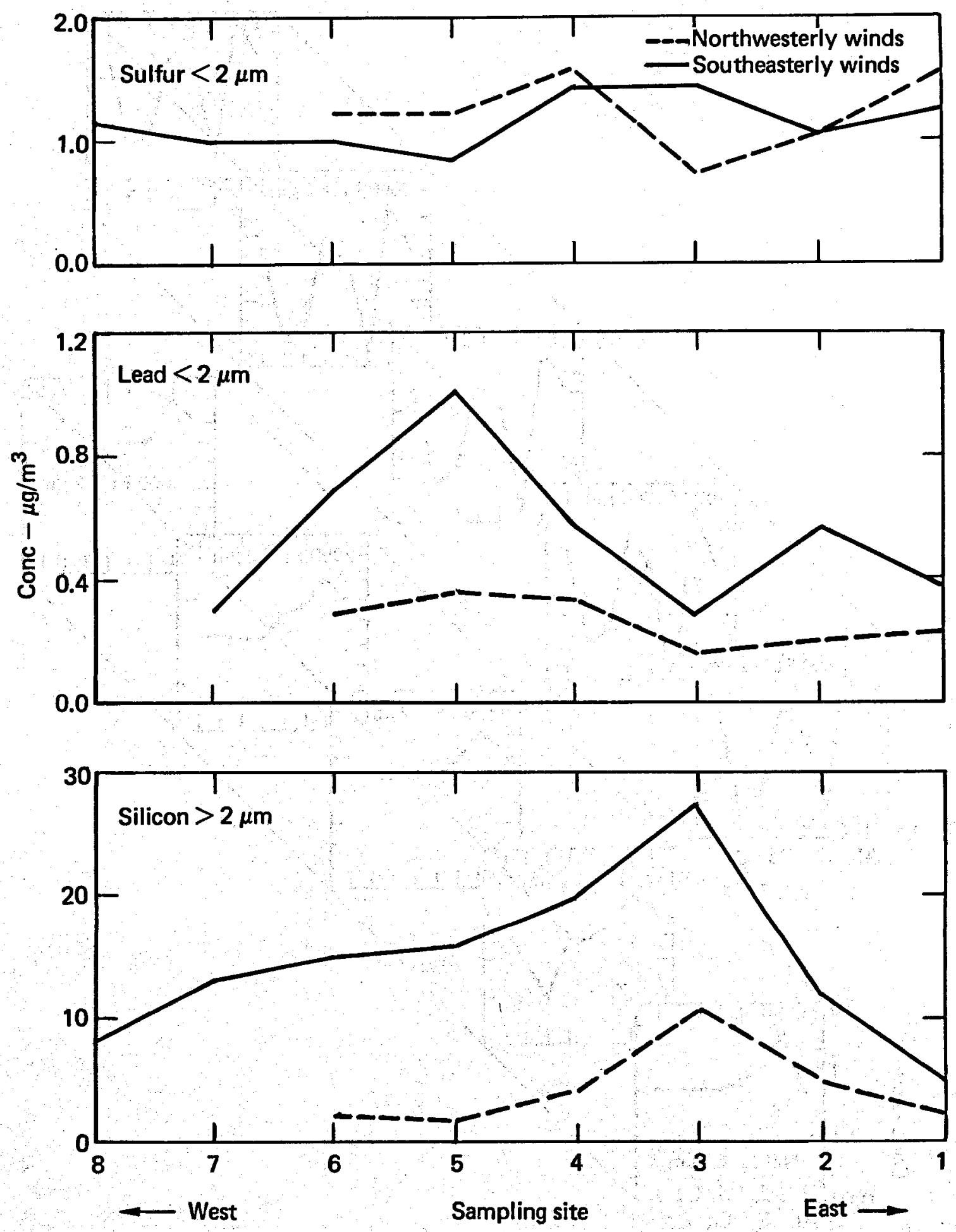

FIG. A-2. The concentrations of sulfur, lead, and silicon in particulate samples collected along the U.S.-Mexico border. 


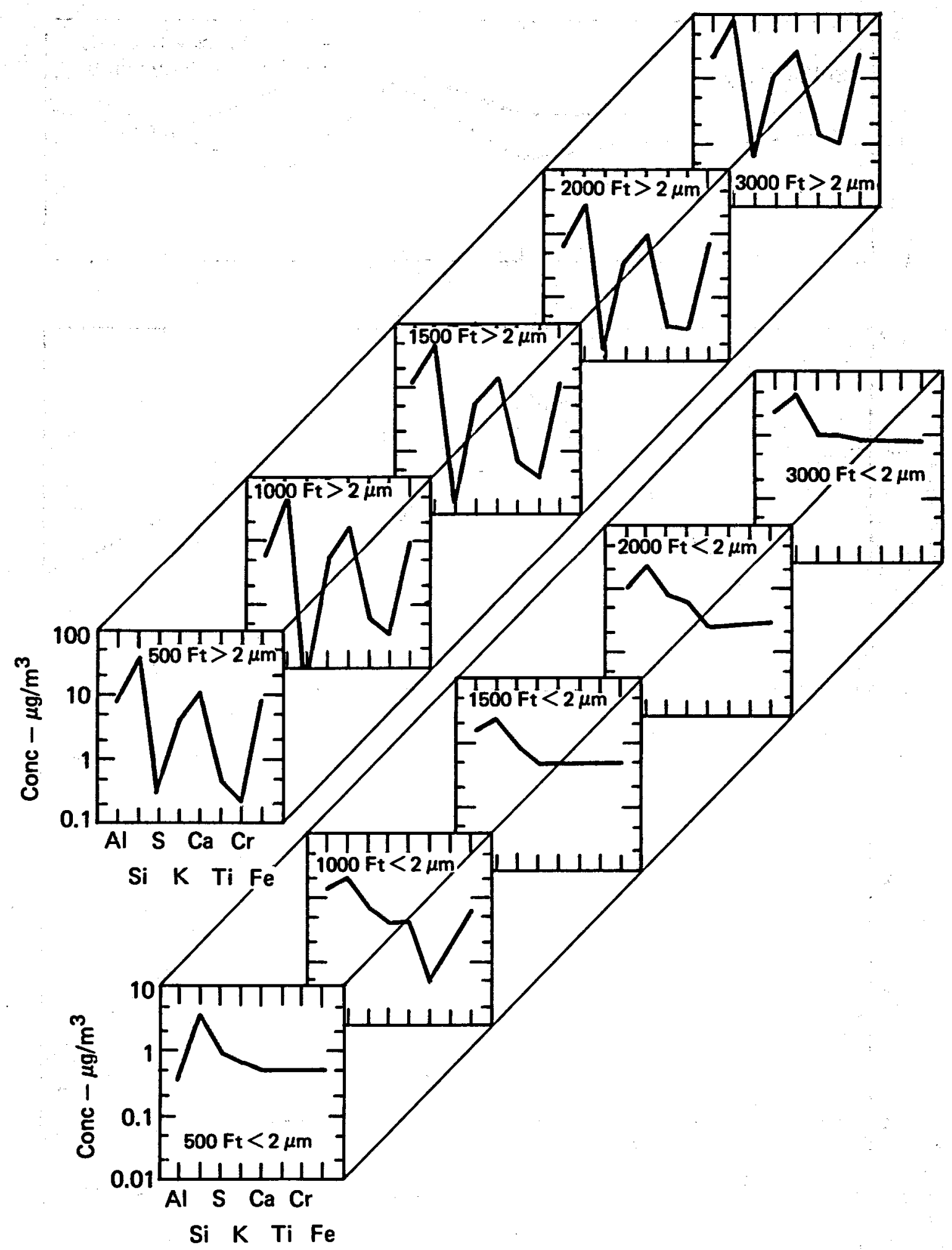

FIG. A-3. Elemental concentrations in particulate samples collected at selected altitudes along the U.S.Mexico border. 